\title{
YAV-8B Reaction Control System Bleed and Control Power Usage in Hover and Transition
}

Paul F. Borchers, Ernesto Moralez III, Vernon K. Merrick, and Michael W. Stortz Ames Research Center, Moffett Field, California

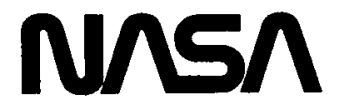

National Aeronautics and

Space Administration 


\begin{tabular}{|c|c|c|c|}
\hline \multicolumn{2}{|c|}{ Nomenclature } & \multirow{3}{*}{$\begin{array}{l}I_{x x} \\
I_{y y} \\
I_{z z}\end{array}$} & \multirow{2}{*}{$\begin{array}{l}\text { aircraft } \mathrm{x} \text {-axis moment of inertia, slug- } \mathrm{ft}^{2} \\
\text { aircraft } \mathrm{y} \text {-axis moment of inertia, slug- } \mathrm{ft}^{2}\end{array}$} \\
\hline $\mathrm{CCOCP}$ & combustion chamber outer casing pressure, & & \\
\hline & & & aircraft $\mathrm{z}$-axis moment of inertia, slug- $\mathrm{ft}^{2}$ \\
\hline HPCT & high-pressure compressor temperature, ${ }^{\circ} \mathbf{K}$ & isen & isentropic \\
\hline JPT & jet pipe temperature & $\mathrm{L}$ & aircraft rolling moment, ft-lbf \\
\hline KIAS & knots indicated airspeed & lw & left-wing RCS nozzle \\
\hline MEBP & main engine bleed pressure, psia & lwd & left-wing downblowing RCS nozzle \\
\hline OWE & operational weight empty & lwu & left-wing upblowing RCS nozzle \\
\hline RACF & $\begin{array}{l}\text { RCS bleed correction factor based on } \\
\text { butterfly valve setting }\end{array}$ & M & Mach number \\
\hline RCS & reaction control system & M & aircraft pitching moment, ft-lbf \\
\hline SAS & stability augmentation system & $\dot{\mathbf{m}}$ & mass flow rate, $\mathrm{lbm} / \mathrm{sec}$ \\
\hline STO & short takeoff & $\dot{\mathrm{m}}_{\text {corr }}$ & $\begin{array}{l}\text { corrected bleed flow rate, } \\
\quad(\mathrm{lbm} / \mathrm{sec})\left(\sqrt{{ }^{\circ} \mathrm{K} / \mathrm{psia}}\right)\end{array}$ \\
\hline STOL & short takeoff and landing & $\mathrm{mfp}$ & corrected mass flow parameter, \\
\hline STOVL & short takeoff and vertical landing & & $(\mathrm{lbm} / \mathrm{sec})\left(\sqrt{ }{ }^{\circ} \mathrm{K} / \mathrm{psia}\right)$ \\
\hline TET & turbine entry temperature & $\mathrm{N}$ & aircraft yawing moment, $\mathrm{ft}-\mathrm{lbf}$ \\
\hline V/STOL & vertical or short takeoff and landing & $\mathbf{P}$ & static pressure, psig \\
\hline VSRA & V/STOL systems research aircraft & $\mathbf{P}_{0}$ & stagnation or total pressure, psia \\
\hline$\Delta \mathbf{P}_{\text {corr }}$ & corrected bleed differential pressure & $\mathbf{R}$ & gas constant for air, $1716 \mathrm{ft}-\mathrm{lbf} /\left(\right.$ slug $\left.^{\circ} \mathrm{R}\right)$ \\
\hline$\delta_{\mathrm{n}}$ & engine nozzle deflection angle from & rw & right-wing RCS nozzle \\
\hline & horizontal, degrees & rwd & right-wing downblowing RCS nozzle \\
\hline$\gamma$ & ratio of specific heats & rwu & right-wing upblowing RCS nozzle \\
\hline$\Delta$ & change in a quantity & $\operatorname{sim}$ & simulation \\
\hline$\theta$ & RCS shutter valve deflection angle, degrees & $\mathrm{T}$ & temperature, ${ }^{\circ} \mathrm{K}$ \\
\hline A & duct cross-sectional area at pressure tap, in ${ }^{2}$ & $\mathbf{T}$ & thrust, lbf \\
\hline$A^{*}$ & $\begin{array}{l}\text { cross-sectional area of flow where } \mathrm{M}=1 \text {, } \\
\text { in }^{2}\end{array}$ & $\mathbf{p}$ & thrust parameter, lbf/psig \\
\hline$A_{R}$ & $\begin{array}{l}\text { ratio of nozzle cross-sectional area to duct } \\
\text { cross-sectional area at a pressure tap }\end{array}$ & $\mathrm{x}$ & aircraft body $x$-axis component \\
\hline ap & aft pitch RCS nozzle & $y$ & aircraft body y-axis component \\
\hline eng & calibrated engine & yaw & yaw RCS nozzles \\
\hline $\mathrm{fp}$ & front pitch RCS nozzle & $\mathrm{z}$ & aircraft body z-axis component \\
\hline
\end{tabular}




\section{Summary}

Using a calibrated Rolls-Royce Pegasus engine and existing aircraft instrumentation and pressure taps, total and individual nozzle reaction control system (RCS) bleed flow rates have been measured on a YAV-8B Harrier during typical short takeoff, transition, hover, and vertical landing maneuvers. RCS thrust forces were calculated from RCS nozzle total pressure measurements, and control power was determined from the moments produced by these thrusts and the aircraft's moments of inertia. These data document the characteristics of the YAV-8B RCS with its basic stability augmentation system (SAS) engaged. Advanced control system designs for the YAV -8B can be compared to the original SAS based on the total bleed use and the percentage of available bleed used. In addition, the peak and mean values of the bleed and control power data can be used for sizing the reaction controls for a future short takeoff and vertical landing (STOVL) aircraft.

\section{Introduction}

All V/STOL aircraft require a system to control attitude in low-speed flight, where the conventional aerodynamic controls are ineffective. In both existing subsonic, and some proposed supersonic, V/STOL fighters, a reaction control system (RCS) is used that diverts high-pressure bleed air from the engine to nozzles located at the aircraft's extremities. The RCS nozzle shutters, which control the RCS thrust forces by changing the nozzle exit areas, are usually connected in parallel with the conventional control surfaces. Since the air bled from the engine reduces the engine thrust available in the flight regime where high thrust is needed, the RCS bleed requirement must be minimized.

Early in the design of the Harrier, the concept of a time mean bleed was established to represent quasi-steady bleed demands that the RCS made on the aircraft engine in hover and V/STOL flight (ref. 1). These "quasi-steady" demands generally represented the control activity to maintain the trim state of the aircraft in hover. Flight measurements on technology-demonstrator aircraft such as the Kestrel established the bleed characteristics for each aircraft axis during various flight phases, as the example in figure 1 shows. The sum of the individual axis bleed rates was used to determine an average bleed demand for the engine during each maneuver. RollsRoyce sized the Pegasus engine to provide constant thrust for bleed levels up to this mean total bleed, with turbine entry temperature (TET) limits dictating a thrust reduction for higher bleed rates (fig. 2). The result of this work is that the Pegasus engine provides sufficient bleed to the Harrier RCS during all phases of flight without seriously degrading the engine thrust.

Designers of future tactical STOVL aircraft need experimentally determined measures of the demands the RCS makes of the Pegasus engine and of the control power the Harrier pilot uses during V/STOL operations. To these ends, total and individual RCS nozzle bleed rate data have been collected during flights of NASA Ames Research Center's YAV-8B Harrier. This same aircraft serves as the V/STOL Systems Research Aircraft (VSRA), which is being used for advanced controls and displays research. These bleed rates, which have never before been measured on this aircraft in flight, may differ somewhat from those used in sizing the original Harrier RCS because the YAV-8B aircraft was flown with its basic SAS engaged. Analysis of the data has yielded the on- and off-axis control power contributions of the RCS bleed during hover maneuvers.

The information presented in this paper serves two purposes. First, data for bleed and control power usage can be compared to data collected during future flights of the VSRA to quantify the changes in bleed demand resulting from the implementation of advanced flight control systems. Second, the bleed and control power data can contribute to the sizing of reaction controls and possibly other low-speed control effectors in new STOVL aircraft designs.

\section{Reaction Control System Description}

Figure 3 shows the layout of the Harrier RCS. The major components of this system are the butterfly valve, the bleed air ducts, and the RCS nozzles. As the aircraft transitions from conventional flight to hover, the butterfly valve opens to pressurize the RCS ducts with air bled from the engine compressor. A mechanical interconnection with the engine nozzle's deflection angle determines the butterfly valve's position, a $36^{\circ}$ engine nozzle deflection corresponding to a fully open butterfly valve. The duct leading away from the butterfly valve splits into two sections leading forward and aft: the forward section supplies bleed air to the front pitch nozzle and to the wing RCS nozzles through two branch ducts, while the aft section leads to two opposed yaw nozzles and a rear pitch nozzle.

The conventional aircraft controls are linked in parallel to the RCS valves so that control is continuous from high speed down to hover. The front pitch RCS valve opens 
with aft longitudinal pilot stick input, producing a noseup pitching moment. The rear pitch valve, geared to stabilator deflection, creates a nose-down pitching moment. Pedal inputs open the yaw valves, producing yawing moments of the same sign as the corresponding rudder deflection. Last, lateral stick deflections open a downblowing wing valve on one or the other of the wing tips to produce a rolling moment of the same sign as the corresponding conventional aileron deflection. For aileron deflections beyond $6.5^{\circ}$ trailing edge downward, the RCS valve on the opposite wing opens as well, but in the upblowing direction. This feature increases the roll control power.

Three of the RCS nozzles and their valve mechanisms appear in four detailed drawings in figure 3. Each valve consists of a shutter that slides over the nozzle exit. In the case of the pitch and roll valves, the shutter pivots about a lug located on the nozzle body itself. The yaw valve shutters share a common attachment arm so that a single rotation opens one valve shutter while simultaneously moving the other shutter to an over-closed position. As the roll valves must provide both upblowing and downblowing bleed flow, the valve shutters on these nozzles can pivot in either direction. For downblowing thrust, the shutter rotates so that its bottom edge is pulled away from the nozzle opening, in a manner similar to that of the other RCS valve operations. The upper portion of the roll valve shutter forms a curved duct so that when the shutter rotates past the closed position with opposite stick input, the air passes into the duct and exhausts in the opposite direction to the normal nozzle flow, producing upblowing thrust. While the RCS valves are mechanically simple, clearances must be maintained between the valve shutter and the nozzle opening so that the shutter will not bind during operation. Since a true seal between the valve shutter and the nozzle is not practical, the RCS leaks whenever the ducts are pressurized, even with the valves nominally closed.

In addition to the pilot's control inputs, a limitedauthority, simplex Stability Augmentation System (SAS) may also command RCS valve deflections. SAS control authority is summarized in table 1 . This system improves the controllability of the aircraft in hover and transition maneuvers, responding primarily to body-axis rotational rates and lateral acceleration. When armed by the pilot, the SAS automatically engages when the flaps or the landing gear are extended and automatically disengages when the aircraft reaches 250 KIAS.
Table 1. Stability augmentation system control authority (ref. 2)

\begin{tabular}{lcc}
\hline \hline $\begin{array}{c}\text { Control surface/ } \\
\text { RCS nozzle }\end{array}$ & $\begin{array}{c}\Delta \text { control } \\
\text { surface } \\
\text { deflection, deg }\end{array}$ & $\begin{array}{c}\Delta \text { RCS } \\
\text { opening, \% of } \\
\text { full open }\end{array}$ \\
\hline Stabilator/front pitch & -1.5 & 28 \\
Stabilator/aft pitch & +1.5 & 19 \\
Aileron/roll & \pm 2.0 & 16 \\
Rudder/yaw & \pm 5.0 & 50 \\
\hline \hline
\end{tabular}

\section{Bleed Flow Measurement Methods}

The next two subsections describe the methods that were used to measure the RCS bleed flow on the YAV-8B Harrier during the flight tests. The first subsection describes the Rolls-Royce Pegasus engine data that were used to calculate the RCS total bleed flow demand. This description is followed by a method for calculating individual RCS nozzle bleed flow rates using previously documented YAV-8B data and pressure tap data recorded during the flight tests.

\section{Total Bleed Flow Measurement}

From tests conducted in 1987, Rolls-Royce developed an RCS calibration curve for the Pegasus engine used in the NASA YAV-8B (ref. 3). Given the temperature from the high-pressure compressor (HPCT), the combustion chamber outer casing pressure (CCOCP), and the main engine bleed pressure (MEBP) from the combustion chamber, the amount of bleed flow that the RCS diverts from the engine can be calculated. The bleed differential pressure is defined as the difference between the combustion chamber outer casing pressure and the main engine bleed pressure. The normalized bleed differential pressure $\Delta \mathrm{P}_{\text {corr }}$ can then be calculated:

$$
\Delta \mathrm{P}_{\text {corr }}=\frac{\text { Bleed Differential Pressure, } \mathrm{psig}}{\text { Main Engine Bleed Pressure, psia }}
$$

The engine calibration equation, as derived from reference 3 , determines the normalized bleed flow rate, $\dot{\mathrm{m}}_{\text {corr }}$, in units of $(\mathrm{lbm} / \mathrm{sec})\left(\sqrt{{ }^{\circ} \mathrm{K} / \mathrm{psia}}\right)$ :

$$
\begin{aligned}
\dot{\mathrm{m}}_{\text {corr }}= & 832.51205\left(\Delta \mathrm{P}_{\text {corr }}\right)^{0.25} \\
& -1350.33211\left(\Delta \mathrm{P}_{\text {corr }}\right)^{0.333} \\
& +667.14185\left(\Delta \mathrm{P}_{\text {corr }}\right)^{0.5} \\
& -122.21912\left(\Delta \mathrm{P}_{\text {corr }}\right)-37.39326
\end{aligned}
$$


The engine bleed flow rate, $\dot{\mathrm{m}}$, in $\mathrm{lbm} / \mathrm{sec}$ can be found from

$$
\dot{\mathrm{m}}=\dot{\mathrm{m}}_{\mathrm{corr}}\left[\frac{\mathrm{MEBP}, \mathrm{psia}}{\sqrt{\mathrm{HPCT},{ }^{\circ} \mathrm{K}}}\right]
$$

Reference 3 states that the bleed flow rates established for the YAV-8B Pegasus engine are consistent with rates from previous RCS calibration tests on earlier builds of this engine.

The available bleed is defined as the maximum amount of bleed air that the engine can supply to the RCS and is a function of MEBP and HPCT. This is distinct from the maximum bleed that the engine could produce at maximum thrust, as the available bleed varies with engine operating condition. Mathematically, the available bleed in $\mathrm{lbm} / \mathrm{sec}$ is found from

$$
\text { Available Bleed }=4.09119 \mathrm{RACF}\left[\frac{\mathrm{MEBP}, \mathrm{psia}}{\sqrt{\mathrm{HPCT},{ }^{\circ} \mathrm{K}}}\right]
$$

where RACF is a pressure-drop correction factor for the position of the RCS butterfly valve. As stated in the description of the RCS, a mechanical interconnection between the engine nozzles and the butterfly valve determines the valve's position. As the engine nozzle deflection angle is decreased, the butterfly valve begins to close, gradually increasing the pressure drop across this valve. Hence, RACF is represented as a function of engine nozzle deflection angle, as shown in table 2.

Table 2. RACF values as a function of engine nozzle angle (ref. 2)

\begin{tabular}{cc}
\hline \hline $\begin{array}{c}\text { Engine nozzle deflection angle, } \delta_{\mathrm{n}} \\
\text { (degrees) }\end{array}$ & $\begin{array}{c}\text { Value for } \\
\text { RACF }\end{array}$ \\
\hline $0^{\circ} \leq \delta_{\mathrm{n}} \leq 2^{\circ}$ & 0 \\
$2^{\circ}<\delta_{n} \leq 15^{\circ}$ & $\left(\delta_{\mathrm{n}}-2^{\circ}\right) / 13^{\circ}$ \\
$\delta_{n}>15^{\circ}$ & 1 \\
\hline \hline
\end{tabular}

\section{Individual RCS Nozzle Bleed Flow Rates}

While the calibrated engine provides total bleed flow information, the allocation of bleed flow to each RCS nozzle requires additional information. The method introduced here uses previously determined nozzle mass flow characteristics obtained from British Aerospace ground tests (ref. 4).

Individual RCS nozzle mass flow rates for the Harrier appear in reference 4 as normalized functions of valve opening. These air flow functions, in the form $(\dot{\mathrm{m}} \sqrt{\mathrm{T}}) / \mathrm{P}_{\mathrm{o}}$, will be termed "mass flow parameters" (mfp) in this report. Modifications to the mfp to more accurately account for RCS nozzle leakage are used in this analysis. These changes are tabulated in appendix A and are documented in reference 5 . Rotary potentiometers located on the RCS valve shutters provided accurate measurements of the valve openings during the flight and ground tests and hence established the mfp for each valve. Temperature and stagnation pressure at each RCS nozzle are the only other measurements necessary for determining the nozzle mass flow rate via the equation

$$
\dot{\mathrm{m}}=\frac{\mathrm{P}_{0}(\mathrm{mfp})}{\sqrt{\mathrm{T}}}
$$

The mass flow rate, $\dot{\mathrm{m}}$, is given in $1 \mathrm{bm} / \mathrm{sec}$, with $\mathrm{P}_{\mathrm{o}}$ in psia and $T$ in degrees Kelvin. According to reference 6 , temperature losses in the RCS ducts are negligible, so the HPCT measurement is used to represent the temperature at each RCS nozzle. Using static pressure measurements near the RCS nozzles, isentropic flow theory in combination with the nozzle mass flow characteristics can be used to derive the stagnation pressure, $\mathrm{P}_{0}$, at each RCS nozzle. A static pressure tap was installed just upstream of the bend in each nozzle, as figure 4 shows. The flow between the pressure tap and the nozzle exit is assumed to be isentropic. In general, the mass flow rate per unit of crosssectional area, $\dot{\mathrm{m}} / \mathrm{A}$, is related to the stagnation pressure, temperature, and Mach number in the following way:

$$
\frac{\dot{\mathrm{m}}}{\mathrm{A}}=\frac{\mathrm{P}_{\mathrm{O}} \sqrt{\gamma}}{\sqrt{\mathrm{RT}}} \mathrm{M}\left(\frac{1}{1+\frac{\gamma-1}{2} \mathrm{M}^{2}}\right)^{\frac{(\gamma+1)}{2(\gamma-1)}}
$$

Since the duct pressure ratio is normally well above the critical value, the RCS nozzle exits are normally choked $(M=1)$. If $A^{*}$ is the cross-sectional area at the nozzle exit, then

$$
\frac{\dot{\mathrm{m}}}{\mathrm{A}^{*}}=\frac{\mathrm{P}_{\mathrm{O}} \sqrt{\gamma}}{\sqrt{\mathrm{RT}}}\left(\frac{2}{\gamma+1}\right)^{\frac{(\gamma+1)}{2(\gamma-1)}}=\frac{\mathrm{P}_{\mathrm{O}}}{\sqrt{\mathrm{RT}}}(0.68473)
$$

where it has been assumed that $\gamma=1.4$. This equation can be solved for $\mathrm{A}^{*}$. Substituting equation (5) for the mass flow rate, using a value of $1716 \mathrm{ft}-\mathrm{lbf} /\left(\mathrm{slug}{ }^{\circ} \mathrm{R}\right)$ for $\mathrm{R}$ and converting to units consistent with the normalized bleed flow data $\left(1.8^{\circ} \mathrm{R} /{ }^{\circ} \mathrm{K}\right.$ and $\left.32.2 \mathrm{lbm} / \mathrm{slug}\right)$, leads to equation 


$$
\mathrm{A}^{*}=2.52167(\mathrm{mfp})
$$

Dividing both sides of equation (8) by the area of the RCS duct at the pressure tap, A, yields the area ratio for sonic flow:

$$
\frac{\mathrm{A}^{*}}{\mathrm{~A}}=\frac{2.52167(\mathrm{mfp})}{\mathrm{A}}
$$

A second expression for this area ratio can be obtained in terms of the Mach number of the flow at the pressure tap, $M$, by dividing equation (6) by equation (7); thus

$$
\frac{\mathrm{A}^{*}}{\mathrm{~A}}=\mathrm{M}\left[\left(\frac{2}{\gamma+1}\right)\left(1+\frac{\gamma-1}{2} \mathrm{M}^{2}\right)\right]^{-\frac{(\gamma+1)}{2(\gamma-1)}}
$$

For $\gamma=1.4$, this becomes

$$
\frac{\mathrm{A}^{*}}{\mathrm{~A}}=1.728 \mathrm{M}\left(\frac{1}{1+0.2 \mathrm{M}^{2}}\right)^{3}
$$

It follows from equations (9) and (11) that

$$
\frac{2.52167(\mathrm{mfp})}{\mathrm{A}}=1.728 \mathrm{M}\left(\frac{1}{1+0.2 \mathrm{M}^{2}}\right)^{3}
$$

Since the mfp is known from reference 4 and $A$ can be measured, equation (12) can be solved for $\mathbf{M}$. This has been carried out through an iterative technique (appendix B). The Mach number, $M$, and the static pressure, $P$, can be used to find the stagnation pressure at the RCS valve through the relationship

$$
\mathrm{P}_{\mathrm{o}}=\mathrm{P}\left[1+\frac{\gamma-1}{2} \mathrm{M}^{2}\right]^{\frac{\gamma}{\gamma-1}}
$$

With the stagnation pressures at each RCS nozzle determined in this way, equation (5) can be used to provide values of $\dot{m}$ for each RCS nozzle. The validity of this method was demonstrated in reference 5 by comparing the results using this method with the results from the RCS portion of the nonlinear simulation model of the aircraft, combined with the total bleed measured by the calibrated engine. A sample of these data appears in appendix A.

\section{RCS Control Power Usage Determination}

The RCS nozzle thrust calculation method that appears in the nonlinear simulation model (ref. 2) was used with the flight test pressure tap data and isentropic flow theory to determine the control power produced by the RCS nozzles in hover maneuvers. The thrust produced at each RCS nozzle, $T_{\text {nozzle, }}$ is determined by the total pressure at the RCS nozzle (psia), the ambient pressure (psig), the nozzle thrust parameter, tp nozzle, and RACF:

$$
\mathrm{T}_{\text {nozzle }}=-\left(\mathrm{P}_{\mathbf{o}_{\text {nozzle }}}-\mathrm{P}_{\mathrm{amb}}\right)\left(\mathrm{tp}_{\text {nozzle }}\right)(\mathrm{RACF})
$$

The thrust parameters for the RCS nozzles were determined as functions of RCS valve deflection in reference 4 and have units of $1 \mathrm{bf} / \mathrm{psig}$. The total pressure values were determined from the static pressure readings near each RCS nozzle and from the isentropic flow assumption described in the previous section. The value of RACF is based on engine nozzle deflection (and hence, butterfly valve setting), as shown in table 2 .

The angle that each RCS nozzle thrust line makes relative to the aircraft was determined from reference 4 as a function of each RCS valve opening. These data were incorporated in the nonlinear simulation model. The RCS thrust forces are then converted into reaction forces in aircraft body-axis components as a function of the respective shutter valve angle, $\theta$. As stated previously, the shutter valve angles were measured directly throughout the tests with rotary potentiometers. From figure 5, the components of the front pitch RCS nozzle thrust in the positive $\mathrm{x}$ and $\mathrm{z}$ directions are

$$
\begin{gathered}
T_{x_{f p}}=-T_{f p} \sin \left(\theta_{f p}-7.63^{\circ}\right) \\
T_{z_{f p}}=T_{f p} \cos \left(\theta_{f p}-7.63^{\circ}\right)
\end{gathered}
$$

Similarly, for the aft pitch RCS nozzle,

$$
\begin{aligned}
& \mathrm{T}_{\mathrm{x}_{\text {ap }}}=\mathrm{T}_{\mathrm{ap}} \sin \left(\theta_{\mathrm{ap}}-8^{\circ}\right) \\
& \mathrm{T}_{\mathrm{z}_{\mathrm{ap}}}=\mathrm{T}_{\mathrm{ap}} \cos \left(\theta_{\mathrm{ap}}-8^{\circ}\right)
\end{aligned}
$$

For the yaw nozzles, thrust directed toward the port side of the aircraft is considered positive (positive side force), and the flow deflection angle is always considered positive. Therefore, the body-axis thrust components are 


$$
\begin{aligned}
& \mathrm{T}_{\mathrm{y}_{\text {yaw }}}=\mathrm{T}_{\text {yaw }} \cos \theta_{\text {yaw }} \\
& \mathrm{T}_{\mathrm{x}_{\text {yaw }}}=-I \mathrm{~T}_{\text {yaw }} \mid \sin \theta_{\text {yaw }}
\end{aligned}
$$

The left-wing downblowing (lwd) and left-wing upblowing (lwu) RCS thrust components are calculated in the following manner, with the reactions from the right-wing thrusts calculated in a similar fashion:

$$
\begin{aligned}
\mathrm{T}_{\mathrm{z}_{\mathrm{lw}}=} & {\left[\mathrm{T}_{\mathrm{lwd}} \cos \left(\theta_{\mathrm{lwd}}+5^{\circ}\right)\right.} \\
& \left.+\mathrm{T}_{\mathrm{lwu}} \cos \left(\theta_{\mathrm{lwu}}+5^{\circ}\right)\right]\left(\cos 7^{\circ}\right) \\
\mathrm{T}_{\mathrm{y}_{\mathrm{lw}}=} & {\left[\mathrm{T}_{\mathrm{lwd}} \sin \left(\theta_{\mathrm{lwd}}+5^{\circ}\right)\right.} \\
& \left.+\mathrm{T}_{\mathrm{lwu}} \sin \left(\theta_{\mathrm{lwu}}+5^{\circ}\right)\right]\left(\cos 7^{\circ}\right) \\
\mathrm{T}_{\mathrm{z}_{\mathrm{rw}}=} & {\left[\mathrm{T}_{\mathrm{rwd}} \cos \left(\theta_{\mathrm{rwd}}+5^{\circ}\right)\right.} \\
& \left.+\mathrm{T}_{\mathrm{rwu}} \cos \left(\theta_{\mathrm{rwu}}+5^{\circ}\right)\right]\left(\cos 7^{\circ}\right) \\
\mathrm{T}_{\mathrm{y}_{\mathrm{rw}}}= & -\left[\mathrm{T}_{\mathrm{rwd}} \sin \left(\theta_{\mathrm{rwd}}+5^{\circ}\right)\right. \\
& \left.+\mathrm{T}_{\mathrm{rwu}} \sin \left(\theta_{\mathrm{rwu}}+5^{\circ}\right)\right]\left(\cos 7^{\circ}\right)
\end{aligned}
$$

The fuel and water levels in the aircraft were measured during the flights. The aircraft's center of gravity in hover was determined from these data and from data from the method used in the nonlinear simulation model. Hence, the effective moment arm distance for each RCS nozzle can be calculated and converted into aircraft body-axis components. The total moment contribution of the RCS in $\mathrm{ft}$-lbf is simply the nozzle thrust multiplied by the respective moment arm, as shown in equations (25-27):

$$
\begin{aligned}
& \mathrm{L}_{R C S_{\text {tot }}}=\mathrm{T}_{\mathrm{z}_{\mathrm{lw}}} \mathrm{y}_{\mathrm{lw}}-\mathrm{T}_{\mathrm{y}_{\mathrm{w}}} \mathrm{z}_{\mathrm{lw}}+\mathrm{T}_{\mathrm{z}_{\mathrm{rw}}} \mathrm{y}_{\mathrm{rw}}-\mathrm{T}_{\mathrm{y}_{\mathrm{rw}}} \mathrm{z}_{\mathrm{lw}} \\
& \mathrm{M}_{\mathrm{RCS}_{\text {tot }}}=\mathrm{T}_{\mathrm{x}_{\mathrm{fp}}} \mathrm{z}_{\mathrm{fp}}-\mathrm{T}_{\mathrm{z}_{\mathrm{fp}}} \mathrm{x}_{\mathrm{fp}}+\mathrm{T}_{\mathrm{x}_{\text {ap }}} \mathrm{z}_{\mathrm{ap}}-\mathrm{T}_{\mathrm{z}_{\mathrm{ap}}} \mathrm{x}_{\mathrm{ap}} \\
& \mathrm{N}_{\text {RCS }}{ }_{\text {tot }}=\mathrm{T}_{\mathrm{y}_{\text {yaw }}} \mathrm{x}_{\text {yaw }}-\mathrm{T}_{\mathrm{x}_{\text {yaw }}} \mathrm{y}_{\text {yaw }}
\end{aligned}
$$

Fuel weight and water weight are also used to determine the moments of inertia for the aircraft in the computer simulation model, in slug- $\mathrm{ft}^{2}$. These same data were used for the inertia calculations in this analysis, with appropriate additions for the landing gear in its extended position:

$$
\begin{aligned}
& I_{x x}=I_{\left.x_{(O W E}+\text { fuel }\right)}+I_{x_{\text {water }}}+I_{x_{\text {gear down }}} \\
& I_{y y}=I_{\left.y_{(\text {OWE }}+\text { fuel }\right)}+I_{y_{y_{\text {water }}}}+I_{y_{y_{\text {gear down }}}} \\
& I_{z}=I_{\left.z_{(\text {OWE }}+\text { fuel }\right)}+I_{z_{\text {water }}}+I_{z_{\text {gear down }}}
\end{aligned}
$$

Dividing the total RCS moments by the respective aircraft inertia yields the RCS control power in terms of bodyaxis angular acceleration, in $\mathrm{rad} / \mathrm{sec}^{2}$.

\section{Description of Flight Tests}

The calibrated engine was used to determine total bleed flow during typical STOVL flight maneuvers, and the pressure-tap data from these flights were used to determine the individual RCS nozzle bleed rates and thrust forces, as described in the previous section. The tests were conducted under calm air conditions, using two standard flight profiles.

One flight profile consisted of hovering maneuvers. After executing a vertical takeoff and stabilizing the aircraft in hover at a 50-ft nominal altitude, the pilot performed lateral and longitudinal translations, followed by pedal turns. The longitudinal translation was accomplished by changing the pitch attitude of the aircraft, while roll attitude changes were used to perform the lateral translation. Maneuvers of this type are used prior to landing after capturing a hover station of fset from the landing pad. These horizontal translations were followed by an aggressive, arrested descent, simulating a waveoff after the initiation of a vertical landing. Each flight ended with a vertical landing on the runway.

The other flight profile incorporated maneuvers representative of STOVL operations. The pilot executed a short takeoff, then returned to the landing area and performed an aggressive, decelerating approach to a stabilized hover, followed by a vertical landing. One flight ended with a slow, rolling landing.

\section{Test Results}

\section{RCS Bleed Air Allocation and Percentage of Available Bleed Used}

Figures 6 through 23 were developed from the total and individual RCS nozzle bleed flow rates measured, in flight, on the YAV-8B. Accumulated over the course of twelve flights, the bleed flow data were grouped 
according to maneuver and arranged in order from the highest to the lowest bleed flow rate. The horizontal axis indicates the percentage of test time for the particular maneuver that a given bleed flow (vertical axis) is exceeded. Using figure 6 as an example, the total bleed curve shows that for $60 \%$ of the time spent in hover, the total bleed rate exceeded $6.0 \mathrm{lbm} / \mathrm{sec}$. Likewise, the total bleed rate exceeded $8.0 \mathrm{lbm} / \mathrm{sec}$ for roughly $4 \%$ of the time spent in hover. It follows that flat portions of these curves indicate recurring bleed rates, as would be recorded for an individual RCS nozzle while the aircraft is in a "quasi-steady" flight condition. Transient control activity produces a greater scatter in the measured bleed data, as seen in the small number of peak bleed data points. The lowest bleed rates often represent leakage bleed flow rates similar to those measured in ground tests in reference 5, encountered when the RCS valves are in their nominally closed settings.

To develop an understanding of the control activity during the maneuvers in hover, the bleed data collected in stabilized hover are discussed first and serve as a baseline for comparison with the remaining flight data. The total bleed curve in figure 6 indicates that the RCS bleed use in hover varies from 9.2 to $4.5 \mathrm{lbm} / \mathrm{sec}$. The individual RCS nozzle bleed flow rates indicate that the roll axis generally uses the greatest amount of bleed air, followed by the pitch axis and then the yaw axis. This bleed allocation generally reflects the sensitivity of the aircraft to disturbances in those axes and to the maneuvers involved, which in turn are strongly influenced by the relative magnitudes of the moments of inertia of the aircraft. The upper $6 \%$ to $8 \%$ of the pitch- and yaw-axis bleed flow rate curves have a steeper slope than the remaining portion of each curve, indicating some transient control activity needed to reject disturbances. The flat portions of the curves, corresponding to bleed flow rates of $0.5 \mathrm{lbm} / \mathrm{sec}$ or less, represent leakage through the nominally closed RCS nozzles.

Since $75 \%$ of the aft pitch nozzle bleed rates exceed the usual aft pitch nozzle leakage rate, and only $15 \%$ of the front pitch nozzle bleed rates exceed the typical front pitch nozzle leakage rate, some amount of aft RCS valve deflection is probably being used to maintain the aircraft trim state. It is also noteworthy that the lateral stick inputs, in combination with the SAS outputs used for hover stabilization, are not of sufficient magnitude to open the upblowing portion of the wing RCS nozzles during any portion of the hover. Bleed usage in hover as a percentage of available bleed has been plotted in figure 7 . This figure indicates that the Pegasus engine could provide twice as much bleed as the maximum used by the RCS in hover. Thus the plot indicates that, in calm air, a relatively small amount of engine bleed air is adequate for the control activity used in maintaining a stabilized hover.

The bleed flow distribution for the first hover maneuver to be examined, longitudinal translation (fig. 8), differs significantly from the stabilized hover bleed flow distribution. First, the upper 15\% of the total bleed curve for the longitudinal translation exceeds the highest total bleed point in the stabilized hover. Second, as the forward and aft stick motions used to initiate and terminate the transition are similar, the front and aft pitch nozzle bleed flow rates are more closely matched in this case than they were in hover, although the aft pitch nozzle once again spends less time than the front pitch nozzle in the nominally closed, leaking position. While the pitch nozzles bleed more air during this translation than in hover, the bleed usage allocation established in the hover case (i.e., roll axis receiving most of the bleed, followed by the pitch and yaw axes) persists for most of this maneuver. Slightly higher bleed rates for the roll and yaw axes, along with a smaller number of leakage bleed rate points, indicate increased activity in the other axes as well. With regard to available bleed air, figure 9 correlates well with the total bleed curve in figure 8, both showing a substantial increase in the bleed air demand over that in the hover case.

Similar changes in the bleed air distribution occur during lateral translations (fig. 10), but the total bleed magnitude is closer to that used in hover. As expected, the downblowing wing nozzles use the greatest amount of bleed air because these nozzles are used to initiate and terminate the maneuver via the roll attitude. Because of the yawing moment due to inlet momentum during the translation, the pilot must use the yaw RCS nozzles to maintain the proper aircraft heading. Consequently, the yaw-axis bleed rates are high relative to hover. The front pitch nozzle bleed rate is nearly identical to the aft pitch nozzle bleed rate, and the bleed rates for each are less than those for either the roll or yaw axes. Overall, the percentage of available bleed used, shown in figure 11, is about $5 \%$ to $13 \%$ higher than that in the hover case. Despite the coupling between the roll and the yaw axes during the lateral translation, the increase in bleed rate from the pitch nozzles during longitudinal translation is greater than that from the roll nozzles during lateral translation, resulting in a higher level of total bleed. This is a consequence of the control power needed to trim the aircraft in pitch and the relatively large pitch moment of inertia of the aircraft.

The RCS bleed distribution during pedal turns in hover appears in figure 12 . The number of data points representing high yaw nozzle bleed rates are indicative of the pilot pedal inputs that were used to arrest the yaw rate of the aircraft. These bleed rate magnitudes result from the 
poor inherent yaw damping of the aircraft in hover. The total bleed curve falls between the levels of bleed used in the longitudinal and lateral translations. The bleed rates of the other RCS nozzles are nearly identical to those in the hover case. The percentage of available bleed used (fig. 13) is generally only slightly greater than that used in the lateral translation, despite the poor inherent yaw damping of the aircraft in hover.

The plot of the bleed air distribution for arrested descents appears as figure 14. The differences between this plot and the hover plot in figure 6 are limited to slightly higher front pitch and roll RCS nozzle control activity during the arrested descent. The total bleed never exceeds $50 \%$ of the available bleed and nearly matches the corresponding plot for hover, as figure 15 shows. Thus, the control activity is essentially that used to maintain a stabilized hover, with the exception of the throttle inputs necessary to initiate the descent and arrest the vertical rate. Apparently no significant changes to aircraft trim occur during the arrested descent.

As expected, the bleed distribution for the vertical landing (fig. 16) is similar to the bleed usage for both the arrested descent and the hover case. The peak bleed values for vertical landings are somewhat higher than those measured during arrested descents. These differences could indicate increased control activity to attain the precision required in landing the aircraft, or could result from trim changes as the aircraft enters ground effect. A few of the peak bleed points in the percentage of available bleed used plot (fig. 17) are all that make this figure different from those generated from the hover and arrested-descent data.

The remaining bleed usage plots (figures 18-23) differ from those presented up to this point because the maneuvers occur at airspeeds where the aerodynamic control surfaces have some effectiveness. The bleed air usage plot for short takeoffs appears in figure 18 . Although the aircraft is accelerating and the aerodynamic controls are becoming more effective as the speed of the aircraft increases, the peak total bleed flow rates for this maneuver are greater than those recorded during any of the other maneuvers. The distribution of bleed air by aircraft axis is similar to that of the other flights, with the exception of the front pitch RCS nozzle bleed flow rate. This nozzle bleed rate exceeds those of the other RCS nozzles for about $30 \%$ of the short takeoff. Figure 19, which shows the percentage of available bleed used, reflects the high bleed rates shown in figure 18 . The bleed plots for the short takeoff may vary from the other plots for two reasons. First, just after the aircraft lifts off the runway, the pilot pitches the nose of the aircraft upward to attain the desired climb angle. The control inputs needed to do this would account for most of the front RCS nozzle bleed rate. Second, since the duration of the short takeoff is less than that of the hover maneuvers, extreme bleed usage during any portion of the short takeoff may skew the results as presented in this format. The mean bleed levels in this maneuver are at least comparable to those in the hover maneuvers, despite the increase in aerodynamic control effectiveness.

In contrast to that for short takeoff, the bleed air distribution for the approach-to-hover phase (fig. 20) indicates that the aerodynamic control surfaces are playing a significant role in the control of the aircraft. The total and individual RCS nozzle bleed rates do not differ much from the bleed rates measured in hover. The pitchaxis bleed air use is somewhat higher, as indicated by both the front and aft pitch nozzle curves. This is probably the result of longitudinal pitch trim changes during the approach to hover; these are caused by engine nozzle deflection angle changes, flap and drooped aileron deflections, and the regulation of aircraft deceleration through pitch attitude angle. The plot of percentage of available bleed used (fig. 21) shows a wide variation in bleed use. Given the relatively low to medium total bleed rates in figure 20 , the highest percentage bleed use probably occurred while the engine nozzle deflection angle and the corresponding RCS butterfly valve setting were small. The availability of bleed air also varies significantly during the approach as the pilot increases the engine thrust and RPM while decelerating the aircraft to zero airspeed. Hence, small RCS valve deflections could bleed off nearly all of the available air at the initiation of the approach, while the same valve deflection at high engine RPM might use only a small percentage of the available bleed air.

Figure 22 shows the allocation of RCS bleed during another type of STOVL approach, the slow, rolling landing. The average bleed levels in this case are similar to those in the approach to hover. With the exception of the upper $7 \%$ of the front pitch RCS nozzle bleed flow rate data, the roll axis requires the majority of the bleed. This difference from the bleed profile for the approach to hover results from the engine nozzle deflection angles used in each case. In the approach to hover, the nozzles are dropped to $81^{\circ}$ during the last phase of the approach. This causes a nose-up pitching moment, which must be countered with aft RCS nozzle bleed. This moment diminishes as the airspeed drops below 50 knots, meaning less bleed is used for trim as the aircraft slows to hover. The engine nozzles during the rolling landing, however, are not deflected beyond $60^{\circ}$, meaning that fewer longitudinal pitch trim changes are required than in the approach to landing. As the aircraft enters ground effect immediately prior to touchdown, some front RCS nozzle 
bleed is used to counter a nose-down moment that is imparted to the aircraft; this appears in figure 22 as the peak bleed point for the front pitch nozzle. The plot for percentage of available bleed used (fig. 23) is not greatly different from the hover plot for the lower $90 \%$ of the bleed data. The highest percentage of bleed used coincides with the front RCS nozzle bleed rate. The available bleed air is less than that in hover because of lower engine RPM during partially wingborne flight. Hence, the front pitch nozzle may be demanding nearly all of the available bleed air at that time of the approach.

\section{Control Power Usage in Hover Maneuvers}

For maneuvers in hovering flight, figures 24-29 illustrate the control power that the RCS provides in terms of angular accelerations. The absolute value of the control power used has been plotted, meaning that the rotational directions of the equivalent angular accelerations have been ignored. The approach in presenting these control power usage profiles will be the same as that used in presenting the allocation of the RCS bleed: the stabilized hover case will be discussed first, and then compared to those of the hover maneuvers.

The plot of the control power usage in hovering flight appears in figure 24 . For the upper $50 \%$ of the data, the roll-axis control power usage is about twice that of the pitch axis. The pitch-axis control usage, in turn, exceeds that of the yaw axis by at least $0.05 \mathrm{rad} / \mathrm{sec}^{2}$ for $70 \%$ of the data. Thus, the control power allocation by axis reflects the bleed air allocation. All of the control power curves drop to $0 \mathrm{rad} / \mathrm{sec}^{2}$, indicating instances when the RCS nozzles are in their nominally closed positions.

The control power usage profile for longitudinal translations appears in figure 25 . The increase in control activity about all axes, as compared to hover, is readily apparent in the higher control power usage and the decrease in the number of data points at $0 \mathrm{rad} / \mathrm{sec}^{2}$. While the bleed allocation plot for this case (fig. 8) showed that the RCS pitch nozzles were using a significant portion of the engine bleed air, figure 25 shows that pitch control power usage has increased about $30 \%$ but is still significantly less than the roll-axis control power usage. While the peak roll and yaw values are only slightly higher than their corresponding peak hover values, the bulk of the control power usage in these axes is greater than in hover. Although this maneuver involves primarily longitudinal dynamics, the control activity about the other axes has increased as well.

The peak control power usage in roll during lateral translations (fig. 26) is nearly twice the peak value for this same axis in hover. The lower $80 \%$ of the roll control power usage data are similar to the longitudinal translation data. While the pitch-axis control power usage is about the same as that used in hover, pilot and SAS compensation for the basic aircraft's poor yaw damping in this maneuver have increased the yaw-axis control power usage to match or exceed that of the pitch axis. While control activity increased in all three axes during the longitudinal translation, the lateral translation dramatically increased the control power usage in the roll and yaw axes. The poor yaw damping results from the yawing moments due to inlet momentum during the lateral translation; these moments tend to point the aircraft away from the direction of the translation.

This lack of inherent yaw rate damping also appears during pedal turns, as reflected in the placement of the yaw and pitch axis curves in figure 27 . The upper $20 \%$ of the yaw-axis control power usage data in this case exceed those of the lateral translation by as much as $0.1 \mathrm{rad} / \mathrm{sec}^{2}$. As in the bleed allocation plot for this maneuver (fig. 12), the upper $8 \%$ of the yaw-axis data points, which form a "plateau" between 0.3 and $0.27 \mathrm{rad} / \mathrm{sec}^{2}$, result from pedal inputs that are used to initiate and terminate the turns. Pitch-axis control activity in this case does not differ much from the activity recorded in either hover or lateral translation, while the roll-axis control power usage is nearly identical to that measured during the longitudinal translation. For most of the time during this maneuver, the relative control power usage allocations by axis are similar to those for other maneuvers.

The control usage profiles for the arrested descent (fig. 28) and vertical landing (fig. 29) differ only in the control activity about the pitch axis. The pitch-axis control power usage for the upper $5 \%$ of the data is greater for the vertical landing, which may be indicative of the control activity associated with a more precise task. Comparing both of these figures with the hover case (fig. 24) reveals that the roll-axis control power usage has significantly increased for these two maneuvers. This reflects the aircraft's sensitivity to disturbances about the roll axis.

\section{RCS Bleed and Control Power Usage Summary}

Table 3 presents the range of total RCS bleed use for each maneuver and flight phase in terms of mass flow rate and percentage of available bleed used. While the peak bleêd numbers in this table are not representative of sustained bleed rates, they do represent peak demands that the RCS could be expected to meet during the course of normal operations. The minimum bleed values are not really significant for the STOL flight phases; for the hover maneuvers, however, they represent a minimum amount of RCS leakage plus any bleed required to maintain the 
aircraft trim state. The table emphasizes the relatively high bleed usage during the hover maneuvers and the wide range of bleed used during the short takeoff (STO). The STOL maneuvers have high peak values for the percentage of bleed used; these peaks may correspond to portions of those flights where the engine RPM, and hence the bleed air available to the RCS, is less than that used in a typical hover.

While the engine must be capable of providing these peak bleed rates to the RCS, a more important characteristic of the Pegasus engine is the sustained bleed rate during hover and STOVL maneuvers that the engine can provide without serious thrust degradation. The mean bleed rates and mean percentages of bleed used in table 4 are representative of the YAV-8B's sustained bleed capabilities for the STOVL maneuvers listed in table 3. While the peak bleed rates in table 3 for the STO maneuvers were

Table 3. Summary of RCS bleed use during maneuvers

\begin{tabular}{|c|c|c|}
\hline Maneuver & $\begin{array}{c}\text { Range of } \\
\text { RCS bleed } \\
\text { use, lbm/sec }\end{array}$ & $\begin{array}{l}\text { nge of RCS bleed } \\
\text { se, as percentage } \\
\text { f available bleed }\end{array}$ \\
\hline Hover & $4.4-9.2$ & $23 \%-50 \%$ \\
\hline $\begin{array}{l}\text { Longitudinal } \\
\text { translation }\end{array}$ & $4.1-14.8$ & $21 \%-88 \%$ \\
\hline Lateral translation & $4.4-11.8$ & $22 \%-64 \%$ \\
\hline Pedal turn & $4.0-12.4$ & $20 \%-70 \%$ \\
\hline Arrested descent & $3.7-9.6$ & $18 \%-49 \%$ \\
\hline Vertical landing & $3.8-11.4$ & $19 \%-94 \%$ \\
\hline STO & $0.2-18.6$ & $2 \%-93 \%$ \\
\hline Approach to hover & $0.9-12.3$ & $8 \%-93 \%$ \\
\hline Slow landing & $3.4-11.8$ & $24 \%-96 \%$ \\
\hline \multicolumn{3}{|c|}{$\begin{array}{l}\text { Table 4. Time mean bleed rates for hover and } \\
\text { STOVL maneuvers }\end{array}$} \\
\hline Maneuver & $\begin{array}{c}\text { Time mean } \\
\text { bleed, } \\
\text { lbm/sec }\end{array}$ & $\begin{array}{c}\text { Mean of } \\
\text { percentage of } \\
\text { bleed used, \% }\end{array}$ \\
\hline Hover & 6.31 & 32.62 \\
\hline Longitudinal transla & 7.29 & 41.01 \\
\hline Lateral translation & 7.32 & 38.83 \\
\hline Pedal turn & 7.16 & 38.39 \\
\hline Arrested descent & 5.97 & 31.73 \\
\hline Vertical landing & 6.00 & 32.29 \\
\hline STO & 6.53 & 34.74 \\
\hline Approach to hover & 5.98 & 45.78 \\
\hline Slow landing & 5.33 & 39.02 \\
\hline
\end{tabular}

high, the longitudinal translation, the lateral translation, the pedal turn in hover, and the slow, rolling landing make a greater average bleed demand on the engine. The mean percentage of available bleed used is about $40 \%$ for each of these maneuvers. The remaining maneuvers use $30 \%$ to $35 \%$ of the available bleed.

Table 5 presents the peak control power use, by axis and maneuver. As was the case in table 3, the RCS must be capable of producing these levels of control power, but these numbers do not represent sustained operation.

Generally, the peak RCS control power use for each axis coincides with the hover maneuver that requires attitude changes about that axis. The roll-axis control power use is greater than the pitch- and yaw-axis control power use for the hover, arrested descent, and vertical landing maneuvers.

Table 5. Peak RCS control power use by axis during hover maneuvers

\begin{tabular}{lccc}
\hline \hline & \multicolumn{3}{c}{ Maximum control power use, rad/sec } \\
Maneuver & Pitch axis & Roll axis & Yaw axis \\
\hline Hover & 0.26 & 0.56 & 0.15 \\
$\begin{array}{c}\text { Longitudinal } \\
\text { translation }\end{array}$ & 0.45 & 0.60 & 0.18 \\
$\begin{array}{c}\text { Lateral } \\
\text { translation }\end{array}$ & 0.26 & 1.23 & 0.20 \\
$\begin{array}{l}\text { Pedal turn } \\
\text { Arrested } \\
\text { descent }\end{array}$ & 0.19 & 0.79 & 0.30 \\
Vertical & 0.14 & 0.63 & 0.15 \\
$\quad$ landing & 0.34 & 0.68 & 0.15 \\
\hline \hline
\end{tabular}

Lastly, the time mean control power usage presented in table 6 is representative of sustained control demands during the hover maneuvers. Since the signs of the control power usage data were dropped, the mean of the control power data as presented figures $24-29$ is the time mean control power usage. The greatest time mean control power use about the pitch and yaw axes coincides with the hover maneuver that requires attitude changes about those axes. The roll-axis time mean control power use shows little variation between the pedal turn, arrested descent, and the lateral and longitudinal translations, despite the differences in the peak values of roll controb usage in table 5. The table 6 values reflect nearly continuous control activity about the roll axis, regardless of the maneuver. 
Table 6. Time mean control power use during hover maneuvers

\begin{tabular}{lccc}
\hline \hline & \multicolumn{3}{c}{ Time mean control power use, rad $/ \mathrm{sec}^{2}$} \\
Maneuver & Pitch axis & Roll axis & Yaw axis \\
\hline $\begin{array}{l}\text { Hover } \\
\text { Longitudinal } \\
\text { translation }\end{array}$ & 0.070 & 0.161 & 0.030 \\
$\begin{array}{c}\text { Lateral } \\
\text { translation }\end{array}$ & 0.106 & 0.389 & 0.037 \\
$\begin{array}{c}\text { Pedal turn } \\
\text { Arrested } \\
\text { descent }\end{array}$ & 0.059 & 0.395 & 0.057 \\
$\begin{array}{c}\text { Vertical } \\
\text { landing }\end{array}$ & 0.050 & 0.396 & 0.075 \\
\hline \hline
\end{tabular}

The relatively high control power demands for both the roll and yaw axes during the pedal turn and the lateral translation show the coupling between these two axes as a result of inlet momentum effects.

\section{Conclusions}

Using a calibrated Rolls-Royce Pegasus engine and existing flight instrumentation, total and individual RCS nozzle bleed flow rates were measured during hover and transition maneuvers of the NASA Ames YAV-8B Harrier. The total bleed data have been presented in terms of mass flow rate and as a percentage of the available engine bleed. The RCS nozzle thrust forces, as determined from the individual RCS nozzle total pressure data, and the aircraft moments of inertia, as determined by the operating aircraft weight plus the fuel and water weights, were used to determine the control power provided by the RCS during these same flights.

Generally, the RCS bleed and control power usage is greatest for the roll axis, followed by that for the pitch axis and then that for the yaw axis. This bleed air distribution reflects the relative sensitivity of the aircraft to disturbances about each axis. Hover maneuvers, such as longitudinal and lateral translations and pedal turns, were found to create the greatest sustained bleed and control power demands. The peak bleed use occurred during STOL flight phases, such as STO and the transition from conventional flight to hover.

The peak bleed and control power use data can be used in sizing the high-bleed, short-duration capabilities of a new. RCS design, while the time mean bleed and mean control power use data indicate long-term, sustained bleed performance that an RCS should provide without degradation of engine thrust. In this manner, the success of the Harrier RCS design can be exploited in the design of future STOVL aircraft. Additionally, the RCS bleed and control power demands presented here can serve as a performance standard for advanced control designs for the Harrier or for the attitude control system of any STOVL aircraft. 


\section{Appendix A}

\section{RCS Nozzle Mass Flow Parameter Adjustments for Leakage}

Ground tests were performed with NASA Ames' YAV-8B to validate the nonlinear simulation model representation of the RCS bleed and leakage. The aircraft was equipped with the duct pressure taps, rotary potentiometers, and the calibrated engine described in the main text. Results from these ground tests are presented in reference 5. Modifications to the mass flow parameters representing leakage are presented here, along with a sample of the test data to illustrate the effects of these changes.

Analysis of these tests compared the RCS bleed determination method of the nonlinear aircraft simulation model and the isentropic flow theory method (as shown in the main text in eqs. (5) through (13)) to total bleed measurements from the calibrated engine. The first ground tests determined the bleed rates through each RCS nozzle when each valve was opened independently of the valves on the remaining RCS nozzles. The engine nozzles were fixed at a $40^{\circ}$ downward deflection from the horizontal, setting the RCS butterfly valve in the fully open position. During the testing of each RCS nozzle, the other valve linkages were disconnected to prevent inadvertent valve openings on the remaining nozzles. Bleed flow data were collected for throttle settings between $85 \%$ and $100 \%$ of maximum RPM, with the pilot opening each valve in a series of stepped control deflections.

Additional bleed flow measurements were recorded with the valves closed, the engine nozzle deflection angle fixed at $40^{\circ}$, and the RPM varied from $85 \%$ to $100 \%$. This provided data on the combined leakage of the valves.

Figure A1 shows typical results using the RCS nozzle mass flow parameter data from reference 4 . Note that the total bleed resulting from the simulation model and from isentropic flow theory generally agree, but disagree with the total bleed calculated from the engine calibration equations by roughly a constant. Both analytical methods predict a higher level of bleed flow usage than was actually demanded from the engine. Since the engine calibration data are considered accurate, an error in the mass flow parameters representing leakage was suspected. These parameters would be "constant" factors when only one valve is open, since the other RCS valves are nominally closed.
To determine if errors existed in the leakage mass flow parameters, the minimum-bleed, fixed engine nozzle data were examined. The total bleed flow measured in this case represents the total installed RCS leakage for the RCS valves in their nominally closed positions. On the basis of these data and the remaining results from the individual valve-opening tests, it was decided to adjust the mass flow parameters representing the valve leakage.

RCS bleed flow data from all of the ground tests involving individual RCS nozzle openings were used to determine the leakage corrections. The total bleed flow as predicted from isentropic flow theory, $\dot{\mathrm{m}}_{\text {tot }}{ }_{\text {isen }}$, and the total bleed flow as predicted by the simulation model, $\dot{\mathrm{m}}_{\text {tot }_{\text {sim }}}$, are the sums of the RCS nozzle bleed flow rates. In mathematical form

$$
\begin{aligned}
& \dot{\mathrm{m}}_{\text {tot }_{\text {isen }}}=\dot{\mathrm{m}}_{\mathrm{fp}_{\text {isen }}}+\dot{\mathrm{m}}_{\mathrm{ap}_{\text {isen }}}+\dot{\mathrm{m}}_{\mathrm{rw}_{\text {isen }}} \\
& +\dot{\mathrm{m}}_{\mathrm{kw}_{\text {isen }}}+\dot{\mathrm{m}}_{\text {yaw }_{\text {isen }}} \\
& \dot{\mathrm{m}}_{\mathrm{tot}_{\mathrm{sim}}}=\dot{\mathrm{m}}_{\mathrm{fp}_{\mathrm{sim}}}+\dot{\mathrm{m}}_{\mathrm{ap}_{\mathrm{sim}}}+\dot{\mathrm{m}}_{\mathrm{rw}_{\mathrm{sim}}} \\
& +\dot{\mathrm{m}}_{\mathrm{lw}} \text { sim }+\dot{\mathrm{m}}_{\text {yaw }} \text { sim }
\end{aligned}
$$

The simulation model and isentropic flow theory calculate reasonable mass flow rates for open RCS nozzles. Hence, the actual leakage is defined as the total mass flow rate determined from the engine calibration minus the amount that is being bled through the currently open RCS nozzle, or

$$
\begin{aligned}
& \dot{\mathrm{m}}_{\text {tot }_{\text {eng }}}-\dot{\mathrm{m}}_{\text {(nozzle in use) }} \text { isen }=\dot{\mathrm{m}}_{\text {leakage }_{\text {isen }}}
\end{aligned}
$$

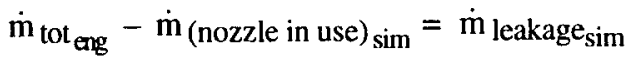

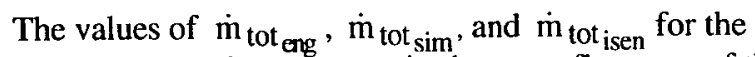
individual nozzle tests contain the mass flow rate of the open RCS nozzle. Therefore, the difference between $\dot{\mathrm{m}}_{\text {tot }}$ and the other total mass flow rates represents the error in the RCS leakage for each calculation method. The percentage error in mass flow leakage for the closed (but still leaking) $R C S$ valves is given by

$\%$ Error in RCS Leakage $=\frac{\text { Error in Total Bleed Flow }}{\text { Actual Leakage }} \times 100 \%$ 
\% Error in RCS Leakage, Isentropic Flow Theory

$$
=\frac{\dot{\mathrm{m}}_{\text {tot }_{\text {eng }}}-\dot{\mathrm{m}}_{\text {tot }_{\text {isen }}}}{\dot{\mathrm{m}}_{\text {leakage }}} \times 100 \%
$$

\% Error in RCS Leakage, Simulation

$$
=\frac{\dot{\mathrm{m}}_{\text {tot }_{\text {eng }}}-\dot{\mathrm{m}}_{\text {tot }_{\text {sim }}}}{\dot{\mathrm{m}}_{\text {leakage }}} \times 100 \%
$$

These errors were averaged between the simulation model and the isentropic flow method and used to recalculate the RCS leakage mass flow parameters. Table A1 lists the original closed-valve mfp values and their revised values. The difference between the new and old $\mathrm{mfp}$ values is approximately $40 \%$.

\begin{tabular}{|c|c|c|}
\hline $\begin{array}{c}\text { RCS } \\
\text { nozzle }\end{array}$ & $\begin{array}{l}\text { Original leakage } \\
\text { mass flow } \\
\text { parameter } \\
\left(\dot{\mathrm{m}} \sqrt{\mathrm{T}} / \mathrm{P}_{\mathrm{o}}\right)\end{array}$ & $\begin{array}{c}\text { Revised } \\
\text { leakage mass } \\
\text { flow parameter } \\
\left(\dot{\mathrm{m}} \sqrt{\mathrm{T}} / \mathrm{P}_{\mathrm{o}}\right)\end{array}$ \\
\hline Front pitch & 0.120 & 0.072 \\
\hline Downblowing wing & 0.150 & 0.089 \\
\hline Upblowing wing & 0.120 & 0.072 \\
\hline Rear pitch/yaw & 0.200 & 0.125 \\
\hline
\end{tabular}

Table A1. Revised RCS nozzle leakage characteristics

Figure A2 shows the total bleed results after the leakage $\mathrm{mfp}$ revision for the same left roll valve input illustrated in figure A1. These revised mfp leakage values were used in the determination of the individual RCS nozzle bleed flow rates presented in this report. 


\section{Appendix B}

\section{Iteration Method to Determine Mach Number at Each Pressure Tap}

Let $A^{*}$ be the cross-sectional area of the RCS nozzle opening, where $M=1$. The duct cross-sectional area where pressure tap $i$ is located is represented by $A_{i}$. The area ratio $A_{R}$ is defined as

$$
A_{R}=\frac{A^{*}}{A_{i}}
$$

The area ratio is used as the initial estimate for the Mach number at the pressure-tap location, $M_{n}$. Equation (B2) determines successive values of Mach number:

$$
M_{n+1}=M_{n}+\Delta
$$

The interval $\Delta$ is determined by the expression

$$
\Delta=\frac{\mathrm{A}_{\mathrm{R}}\left(1+0.2 \mathrm{M}_{\mathrm{n}}^{2}\right)^{3}-1.728 \mathrm{M}_{\mathrm{n}}}{1.728-1.2 \mathrm{~A}_{\mathrm{R}} \mathrm{M}_{\mathrm{n}}\left(1+0.2 \mathrm{M}_{\mathrm{n}}^{2}\right)^{2}}
$$

The iteration on Mach number continues until the absolute value of $\Delta$ is less than $1 \times 10^{-6}$. The stagnation pressure calculation, equation (13) in the text, uses this final value of Mach number.

The remainder of the appendix shows the derivation of equation (B3) from isentropic flow theory. $M_{i}$, the Mach number at the pressure tap, is related to $A_{R}$ and the ratio of specific heats, $\gamma$, as follows:

$$
A_{R}=M_{i}\left[\left(\frac{2}{\gamma+1}\right)\left(1+\frac{\gamma-1}{2} M_{i}^{2}\right)\right]^{-\frac{(\gamma+1)}{2(\gamma-1)}}
$$

Assuming $\gamma=1.4$ for air

$$
A_{R}=\frac{1.728 M_{i}}{\left(1+0.2 M_{i}^{2}\right)^{3}}
$$

Let $M_{i}=M_{n}+\Delta$, $|\Delta|<M_{n}$, where $M_{n}$ equals an initial estimate of $M_{\mathrm{i}}$. Substituting into equation (B5):

$$
A_{R}=\frac{1.728\left(M_{n}+\Delta\right)}{\left[1+0.2\left(M_{n}+\Delta\right)^{2}\right]^{3}}
$$

Expanding the denominator

$$
A_{R}=\frac{1.728\left(M_{n}+\Delta\right)}{\left[1+0.2\left(M_{n}^{2}+2 M_{n} \Delta+\Delta^{2}\right)\right]^{3}}
$$

Assuming $\Delta^{2}$ is small

$$
A_{R} \approx \frac{1.728\left(M_{n}+\Delta\right)}{\left(1+0.2 M_{n}^{2}+0.4 M_{n} \Delta\right)^{3}}
$$

$$
\approx \frac{1.728\left(M_{n}+\Delta\right)}{\left(1+0.2 M_{n}^{2}\right)^{3}\left[1+\frac{1.2 M_{n} \Delta}{\left(1+0.2 M_{n}^{2}\right)}\right]}
$$

Solving for $\Delta$

$$
\begin{array}{r}
A_{R}\left(1+0.2 M_{n}^{2}\right)^{3}+A_{R}\left(1.2 M_{n} \Delta\right)\left(1+0.2 M_{n}^{2}\right)^{2} \\
=1.728\left(M_{n}+\Delta\right)
\end{array}
$$

$$
\Delta=\frac{\mathrm{A}_{\mathrm{R}}\left(1+0.2 \mathrm{M}_{\mathrm{n}}^{2}\right)^{3}-1.728 \mathrm{M}_{\mathrm{n}}}{1.728-1.2 \mathrm{~A}_{\mathrm{R}} \mathrm{M}_{\mathrm{n}}\left(1+0.2 \mathrm{M}_{\mathrm{n}}^{2}\right)^{2}}
$$




\section{References}

1. Fozard, John W.: The Jet V/STOL Harrier-An Evolutionary Revolution in Tactical Air Power. British Aerospace Aircraft Group, KingstonBrough Division, July 1978.

2. McDonnell Aircraft Company: YAV-8B Simulation and Modeling, Volume 1: Aircraft Description and Program Summary. NASA CR-170397, March 1983.

3. Eames, D. J. H.: Pegasus Engine 8735 Bleed Flow Calibration at Patuxent River. Rolls-Royce Inc. ATLR 0703, December 1987.
4. Melsom, R. K.; and Gerhold, M. N.: AV-8B Reaction Control System Performance. British Aerospace P. L. C. report number BAe-KGT-RV8B-01100, January 1982.

5. Borchers, P. F.; Moralez, E.; Merrick, V. K.; Stortz, M. W.; and Eames, D. J. H.: Determination of YAV-8B Reaction Control System Bleed Flow Usage. AIAA-92-4232, August 1992.

6. Ruscoe-Pond, M. G.: Harrier Reaction Control Data. British Aerospace P. L. C. report number P. O. N. 1216, December 1967.
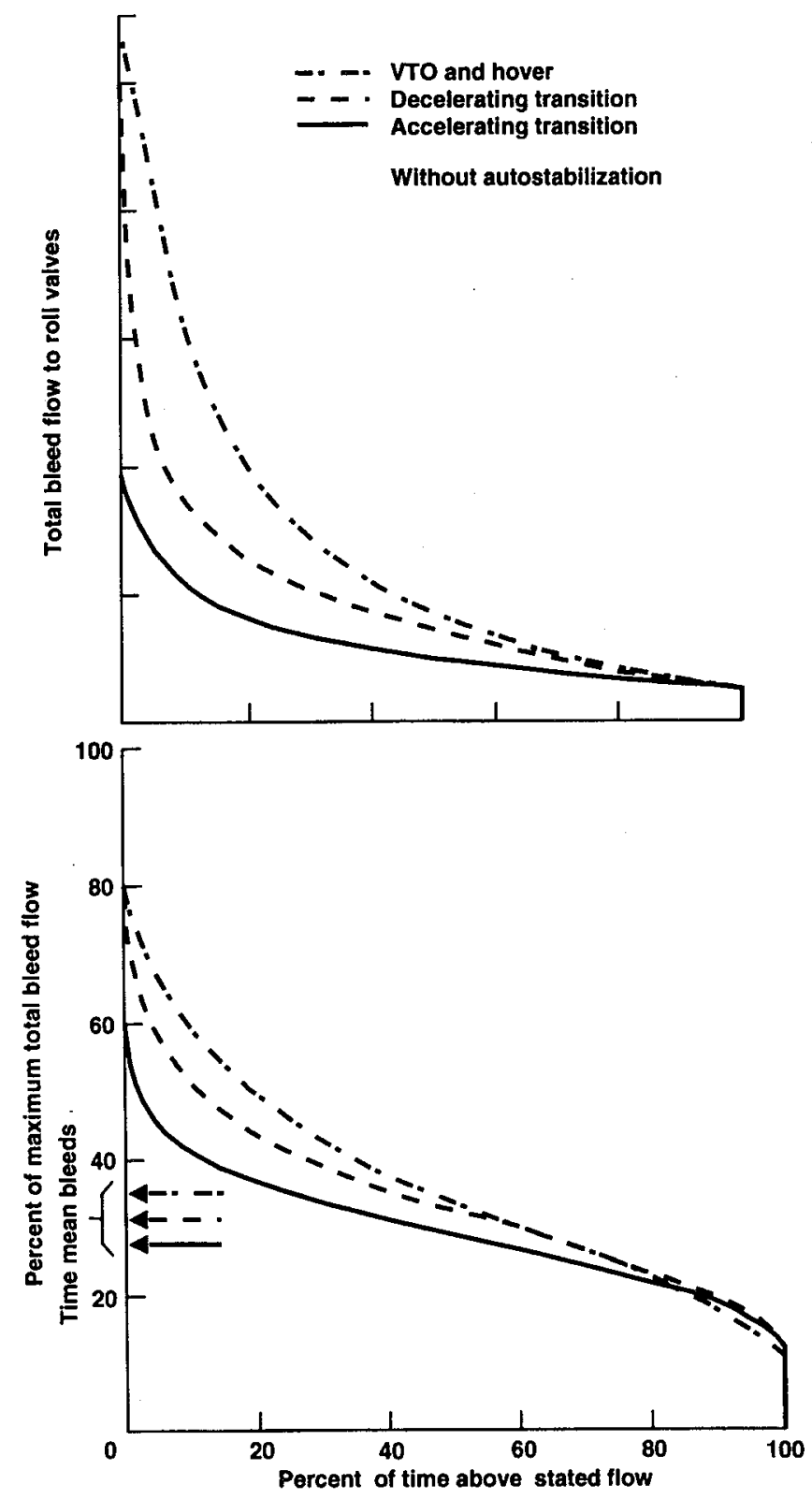

Figure 1. Typical bleed usage for Harrier technology-demonstrator aircraft (adapted from ref. 1). 


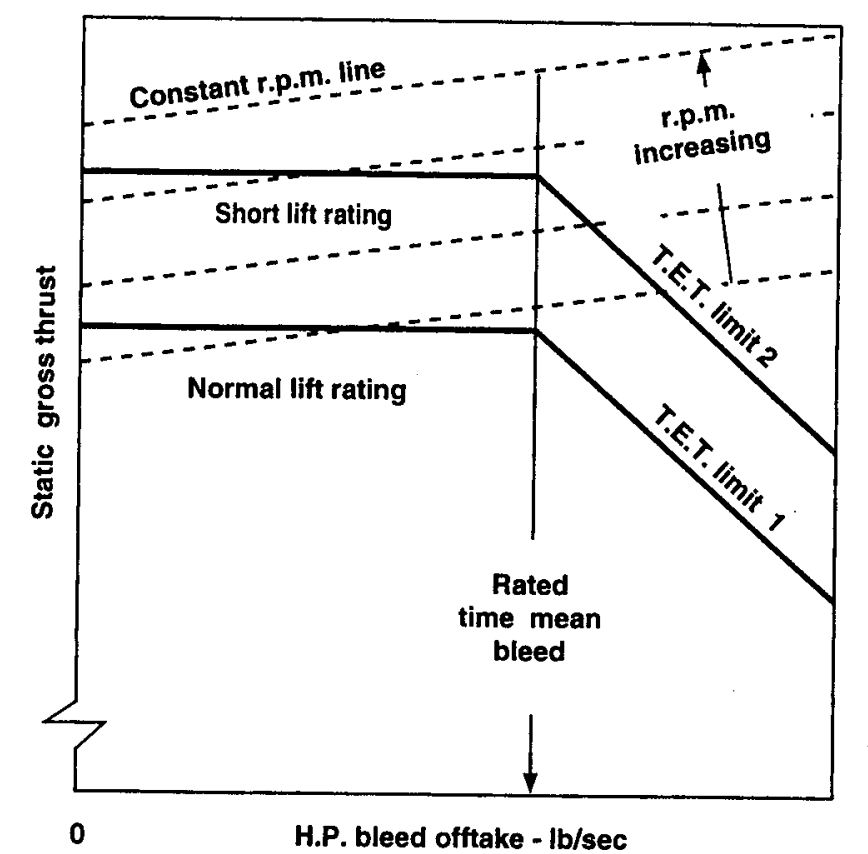

Figure 2. Engine lift rating for the Harrier (adapted from ref. 1).

(A) Nozzle bodies

(B) Valve shutters

(C) Actuator linkage

\section{Forward pitch RCS valve} (side view)

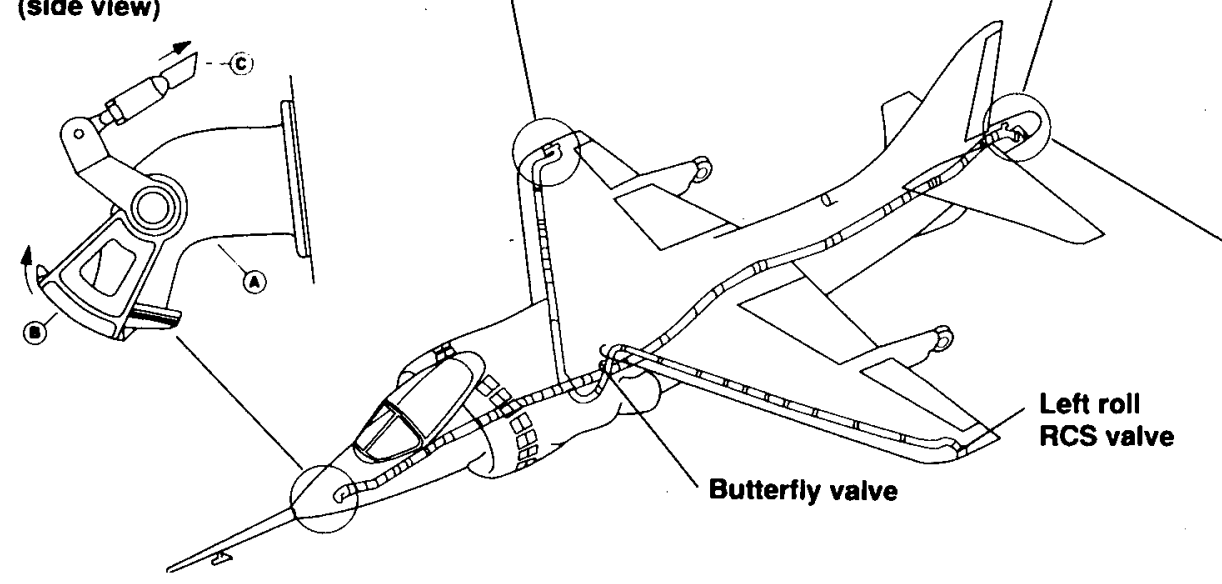

Yaw/aft pitch RCS valve

(top view)

Right roll RCS valve (front view)
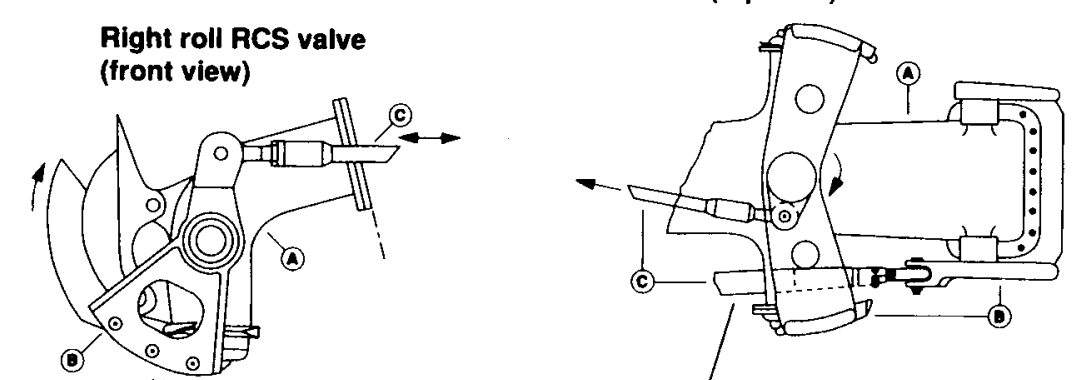

Figure 3. RCS layout with RCS nozzle and valve details. 


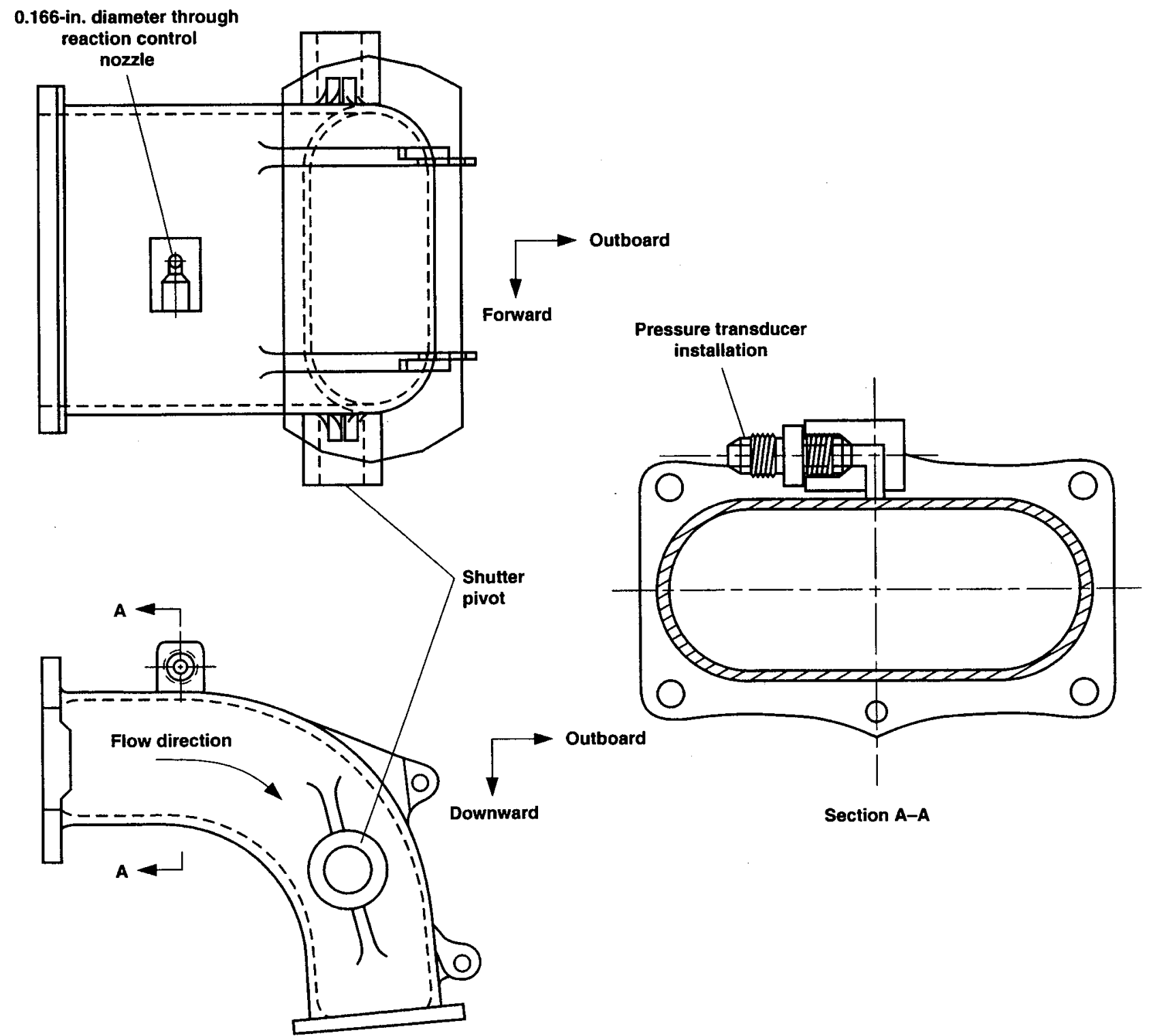

Figure 4. Typical RCS pressure-tap installation (roll nozzle). 


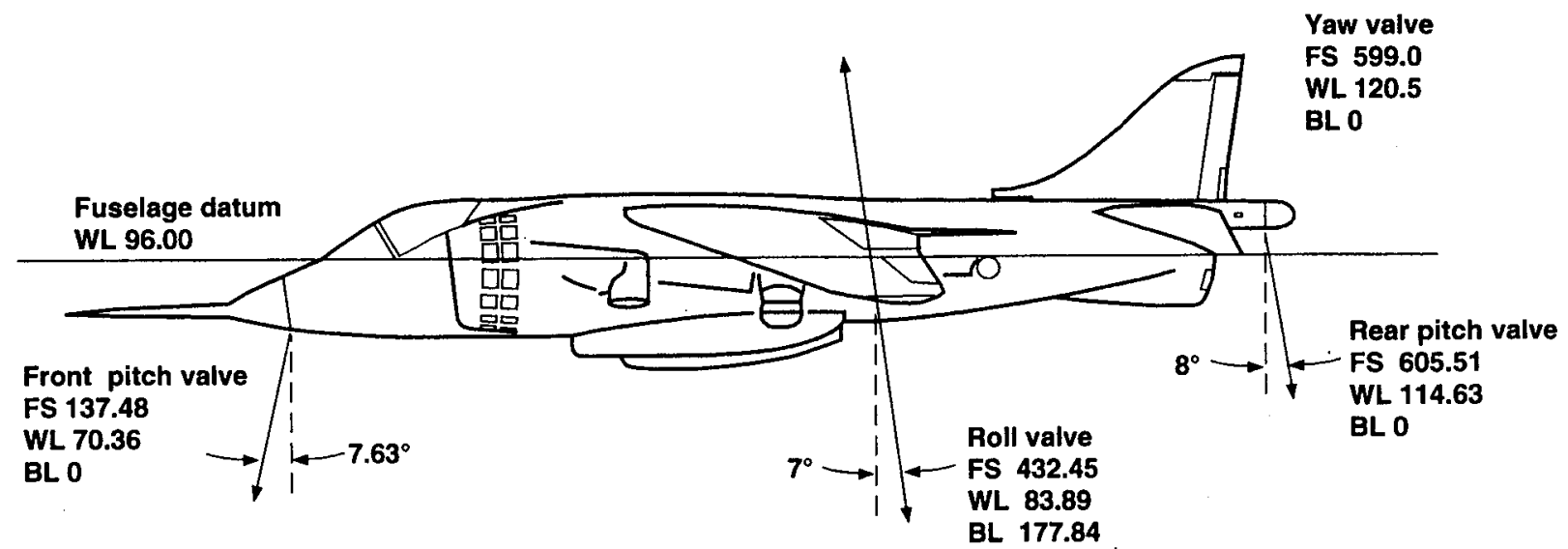

Right roll valve

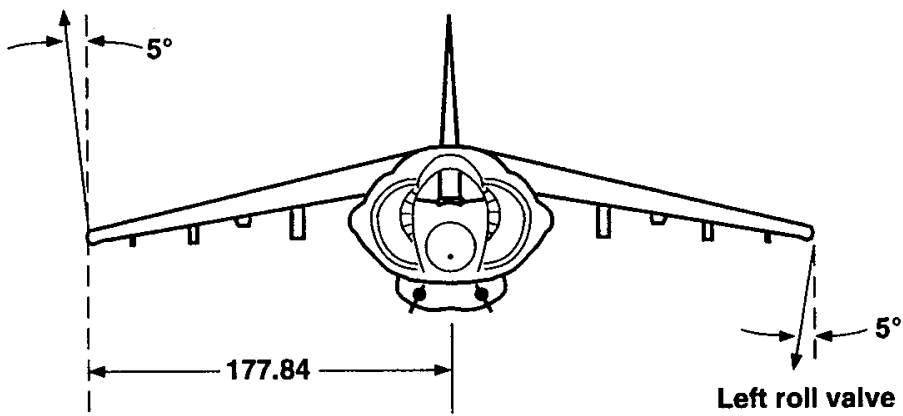

All dimensions in inches

FS - fuselage station

WL. water line

BL - butt line

Figure 5. YAV-8B reaction control nozzle locations and thrust lines for maximum shutter deflection (as taken from ref. 2). 


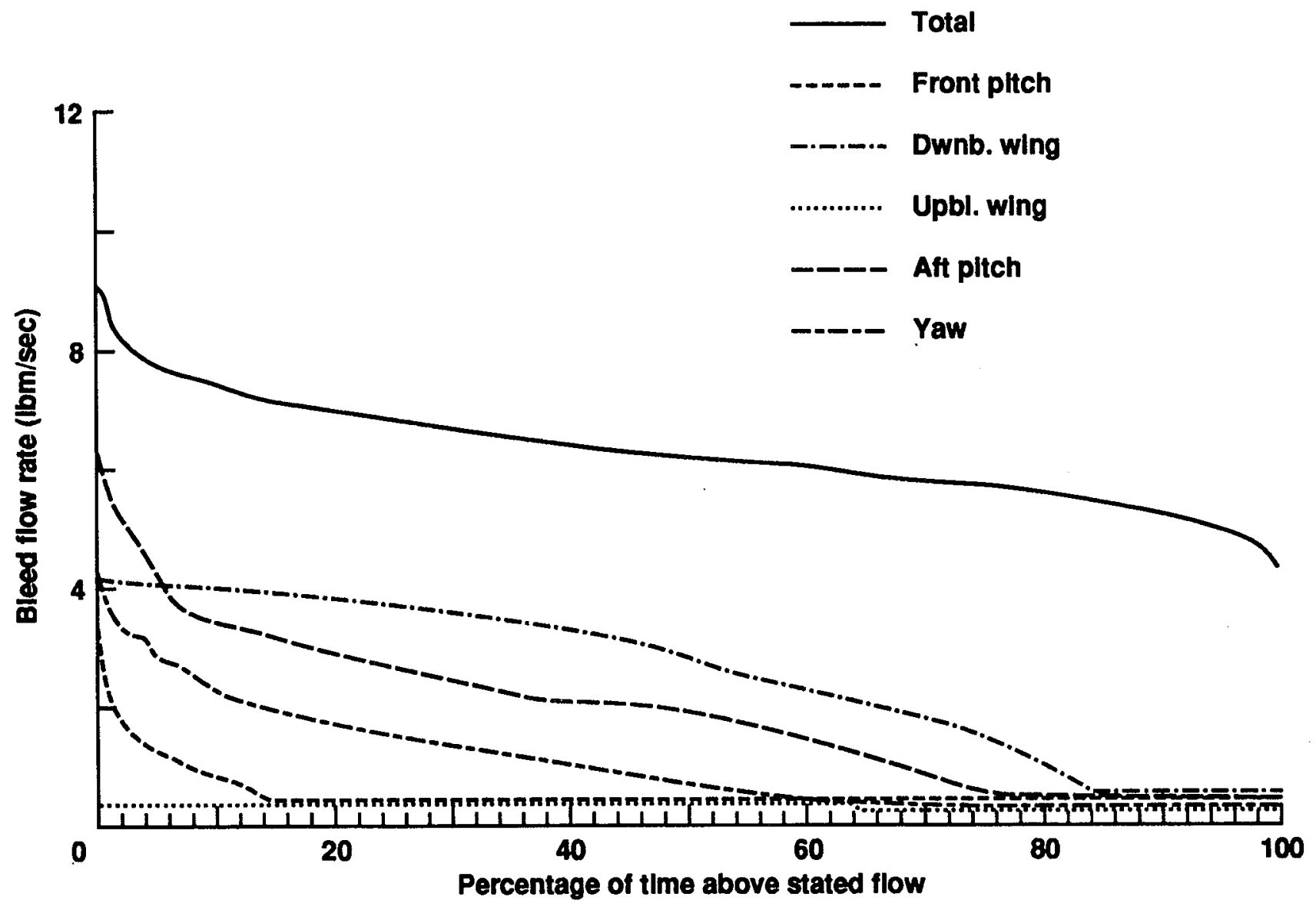

Figure 6. RCS bleed air usage during hover. 


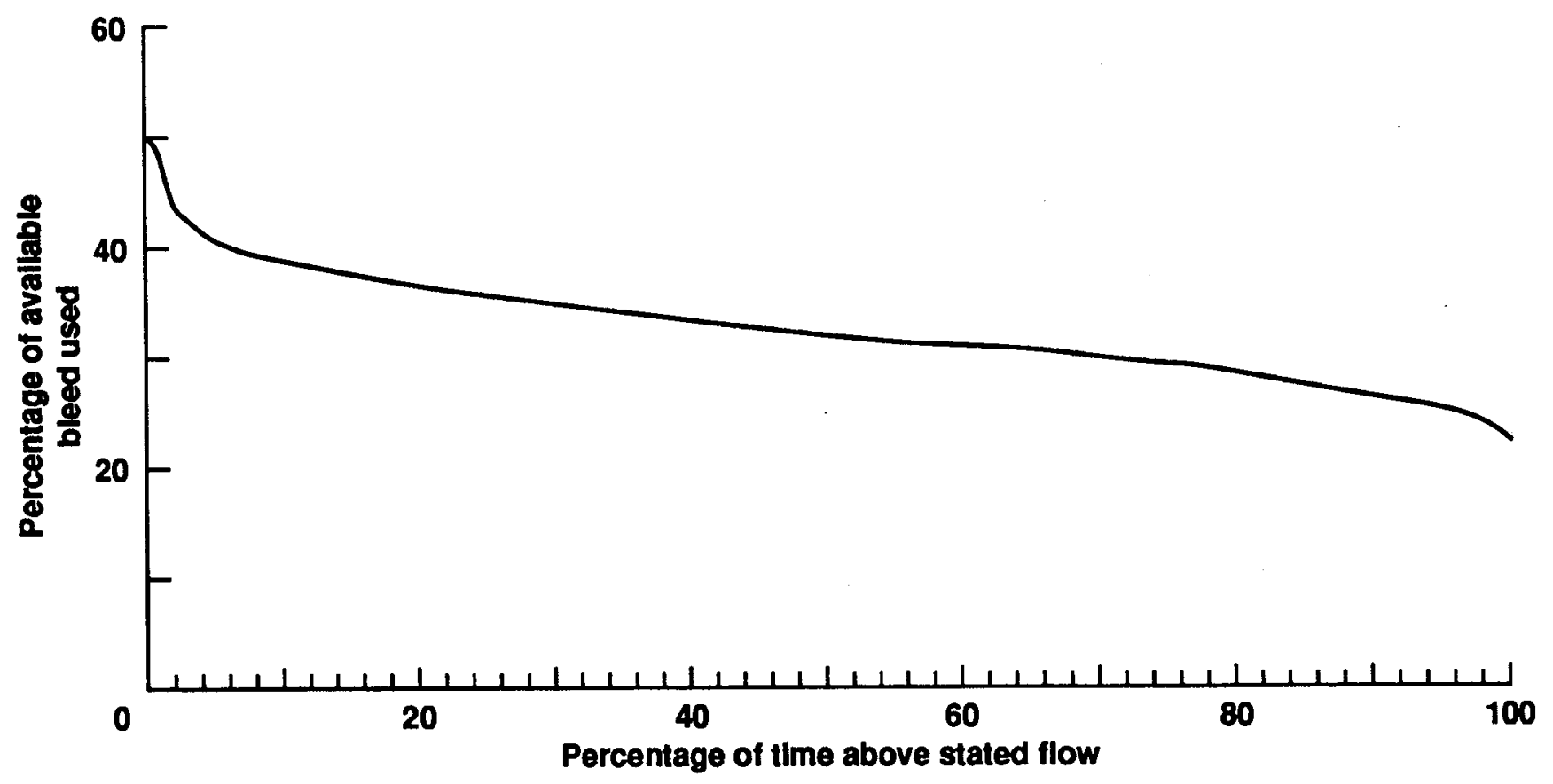

Figure 7. Percentage of available RCS bleed air used during hover. 


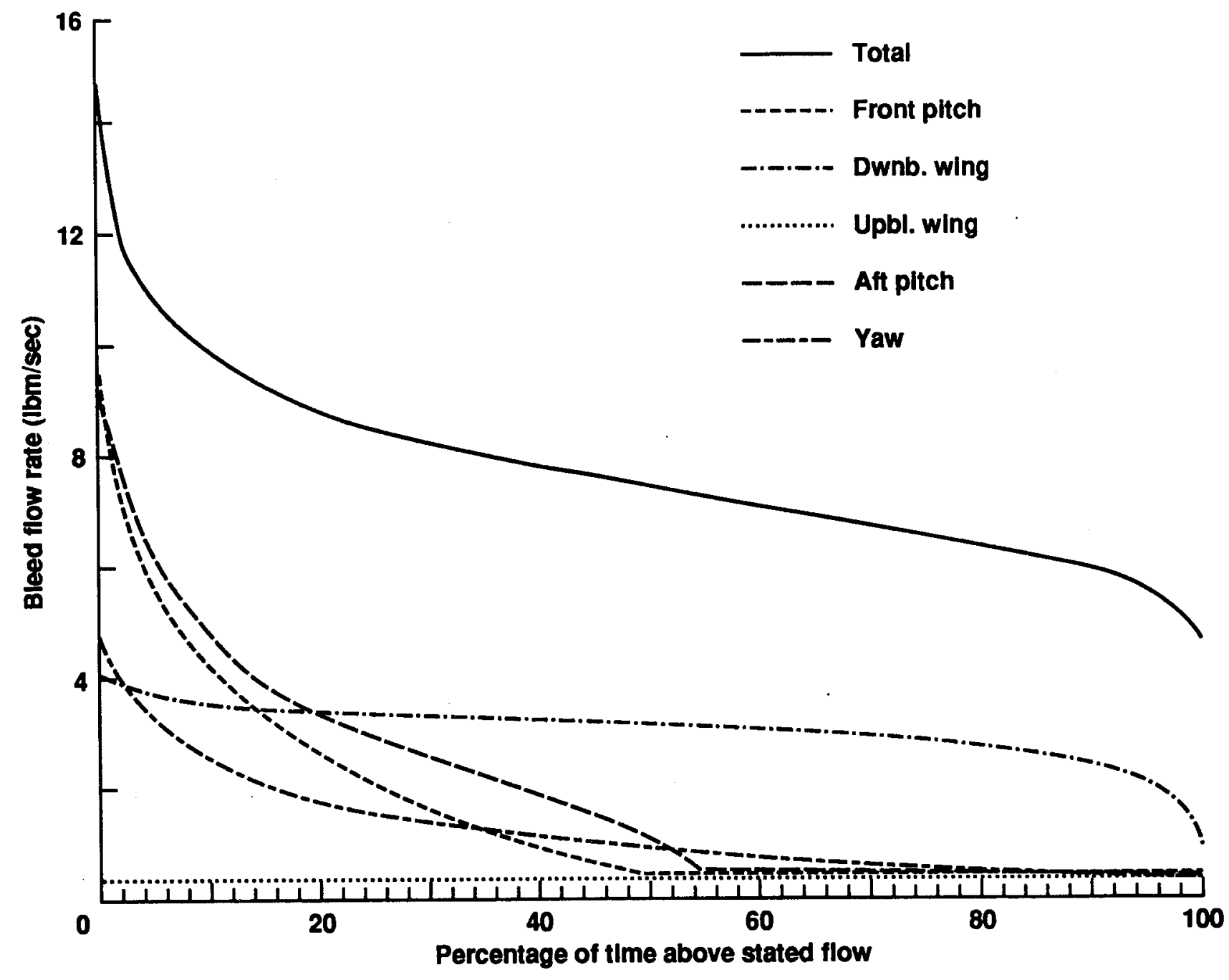

Figure 8. RCS bleed air usage during longitudinal translations. 


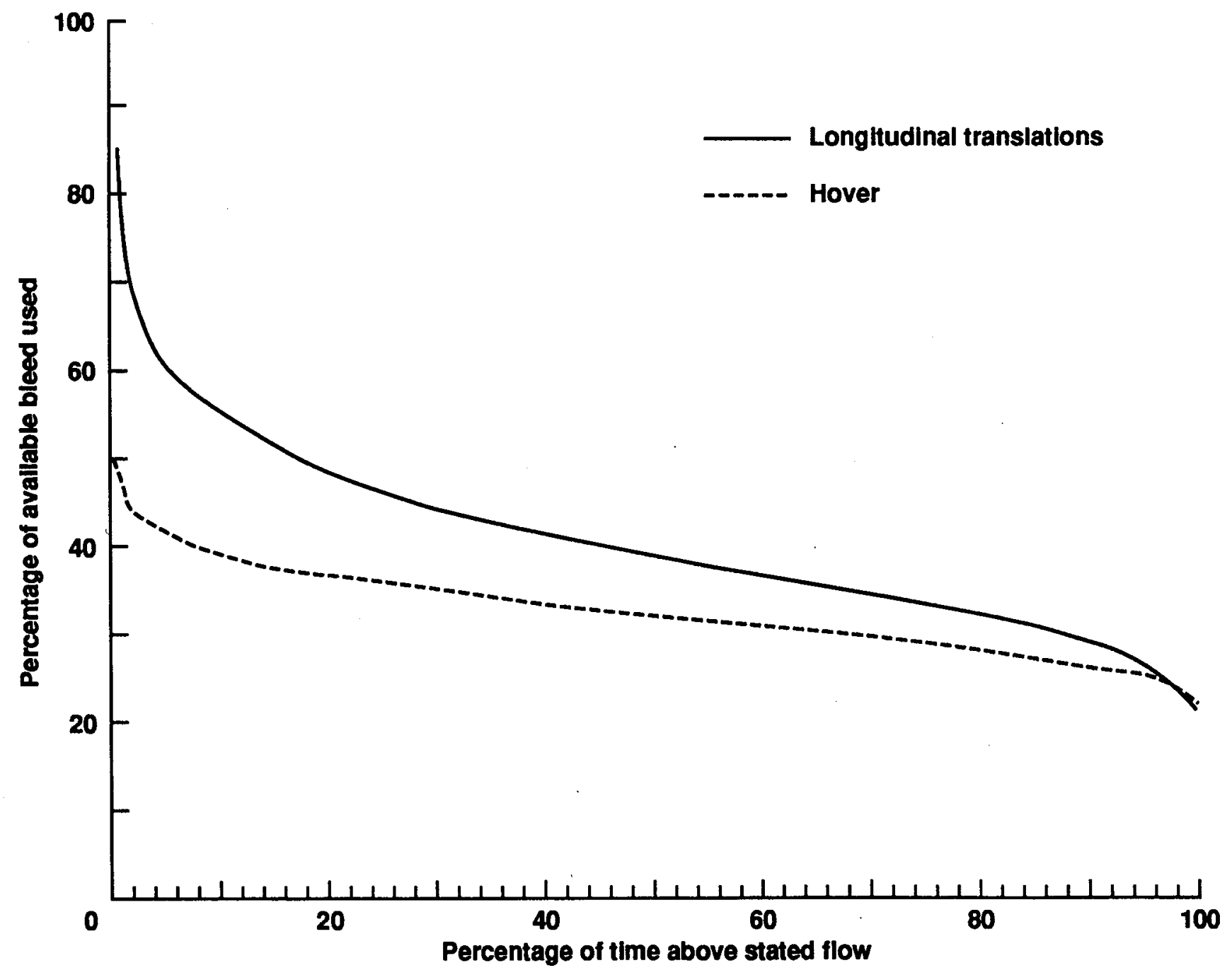

Figure 9. Percentage of available RCS bleed air used during longitudinal translations. 


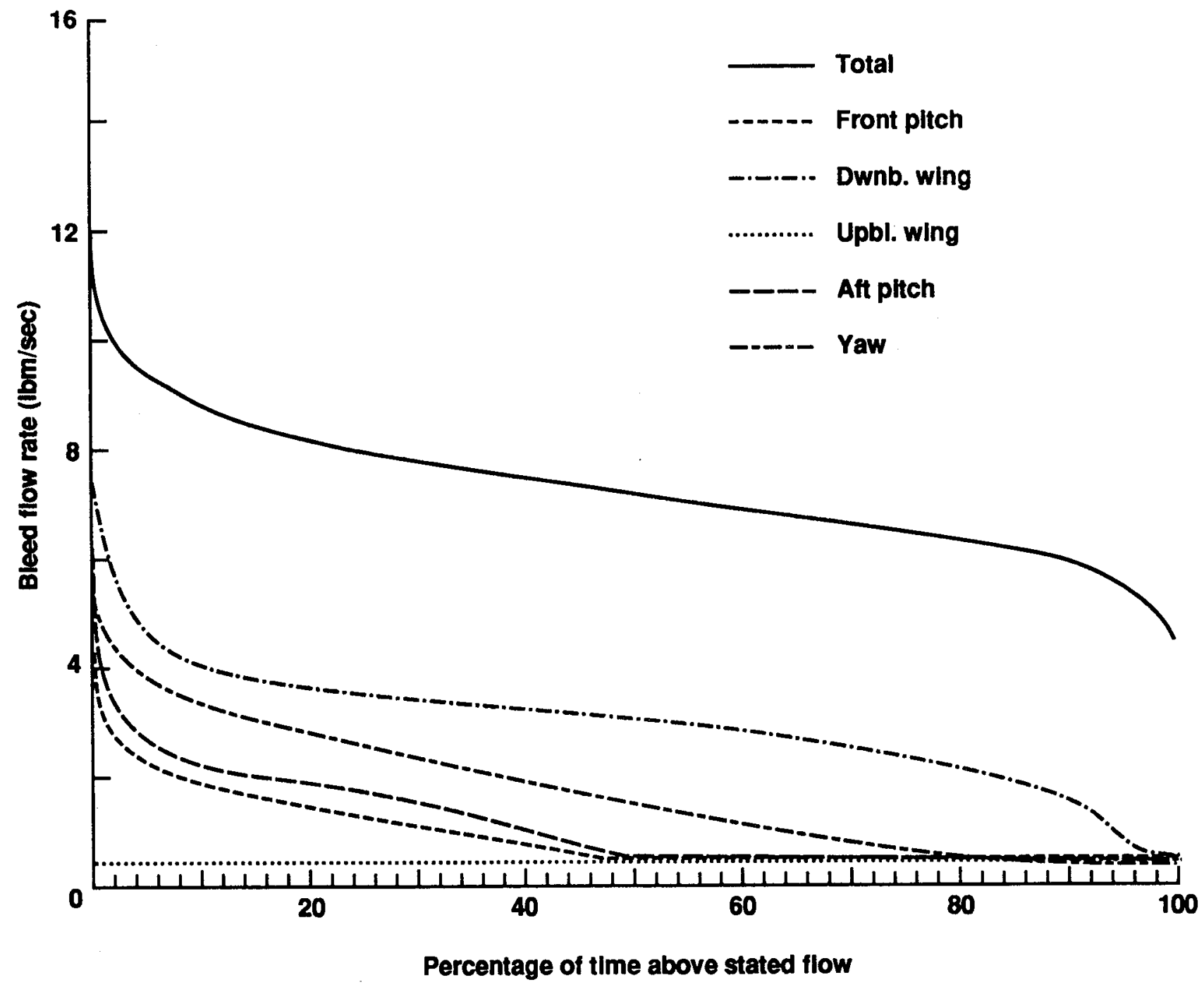

Figure 10. RCS bleed air usage during lateral translations. 


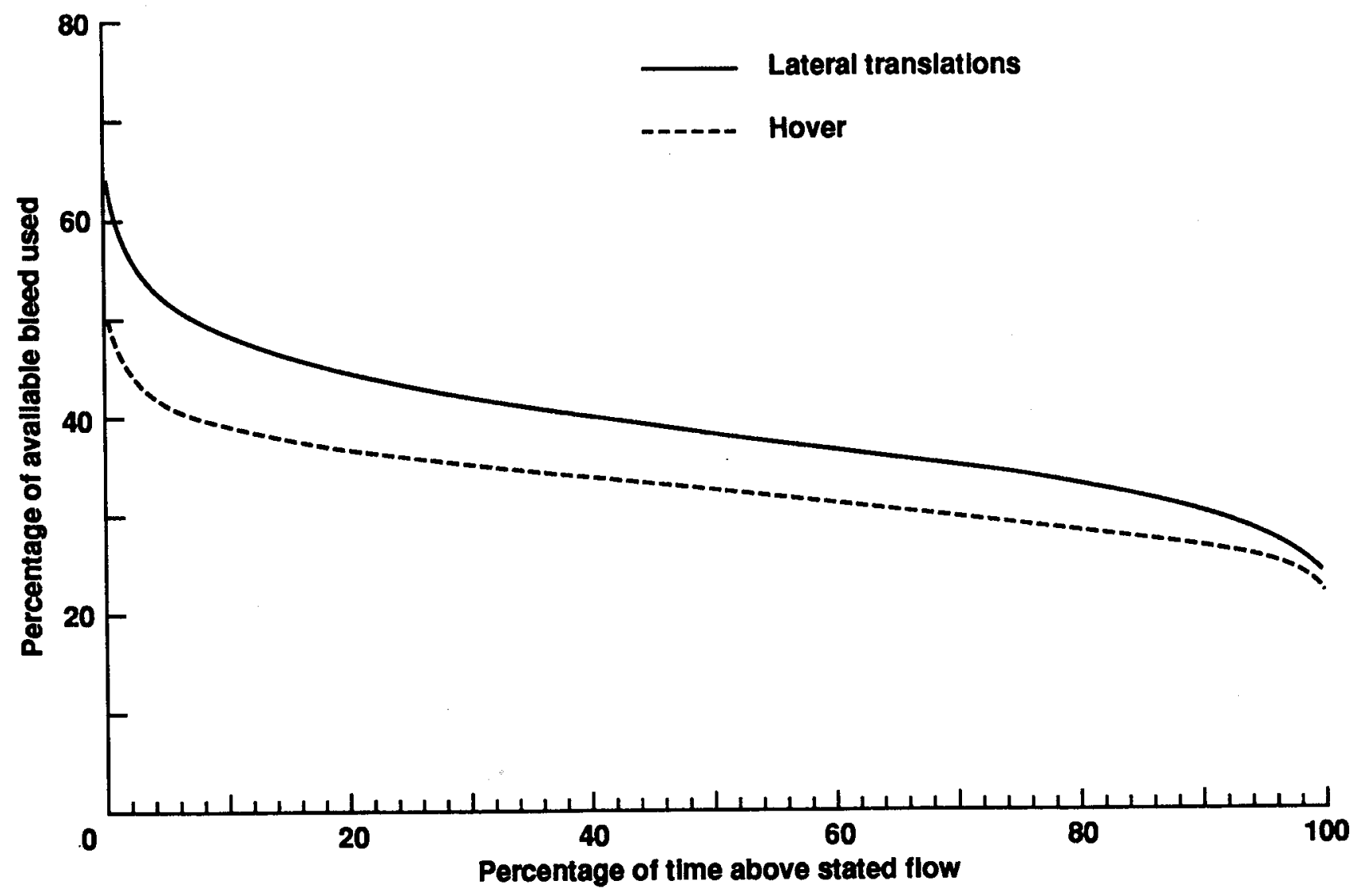

Figure 11. Percentage of available RCS bleed air used during lateral translations. 


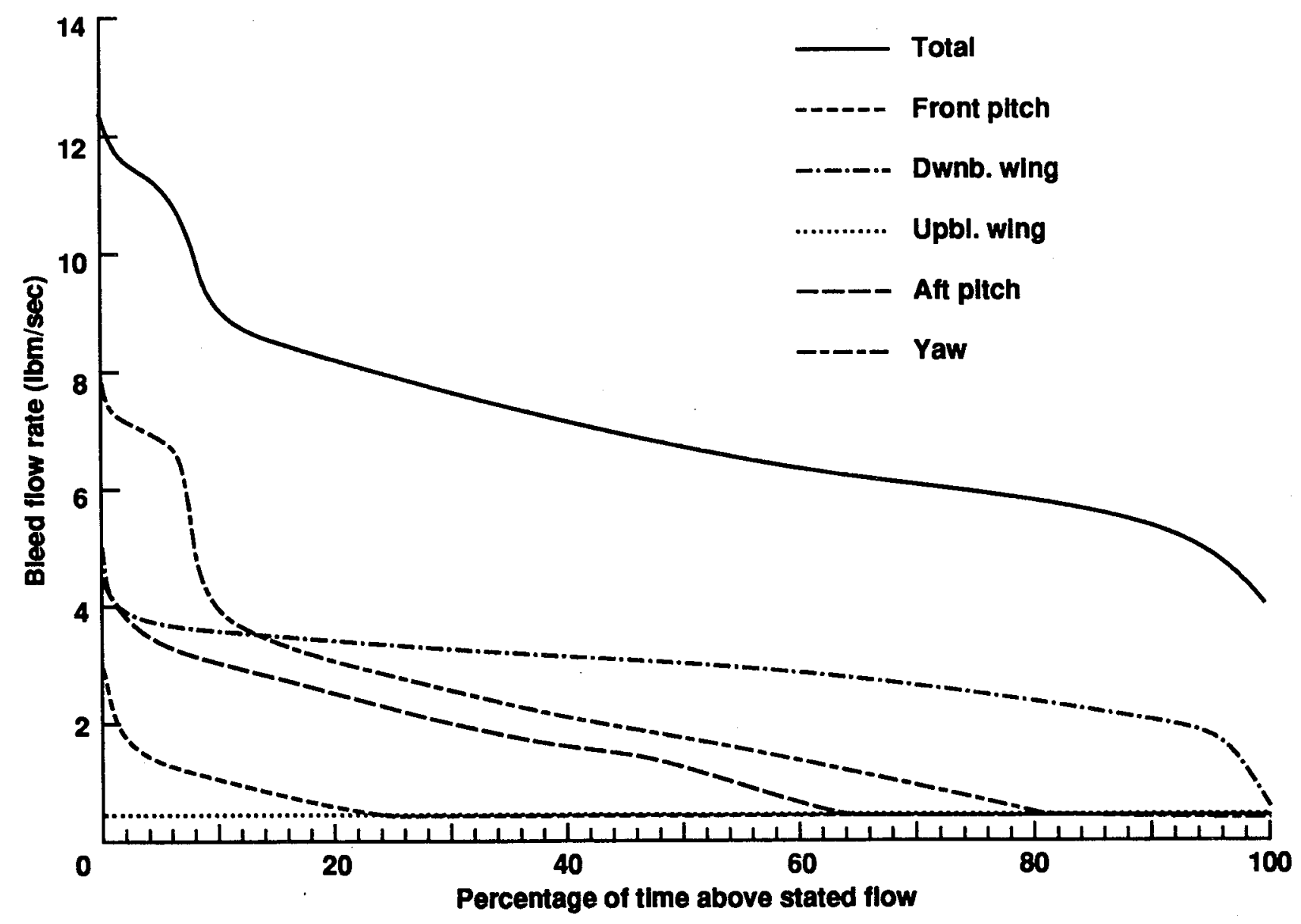

Figure 12. RCS bleed air usage during pedal turns. 


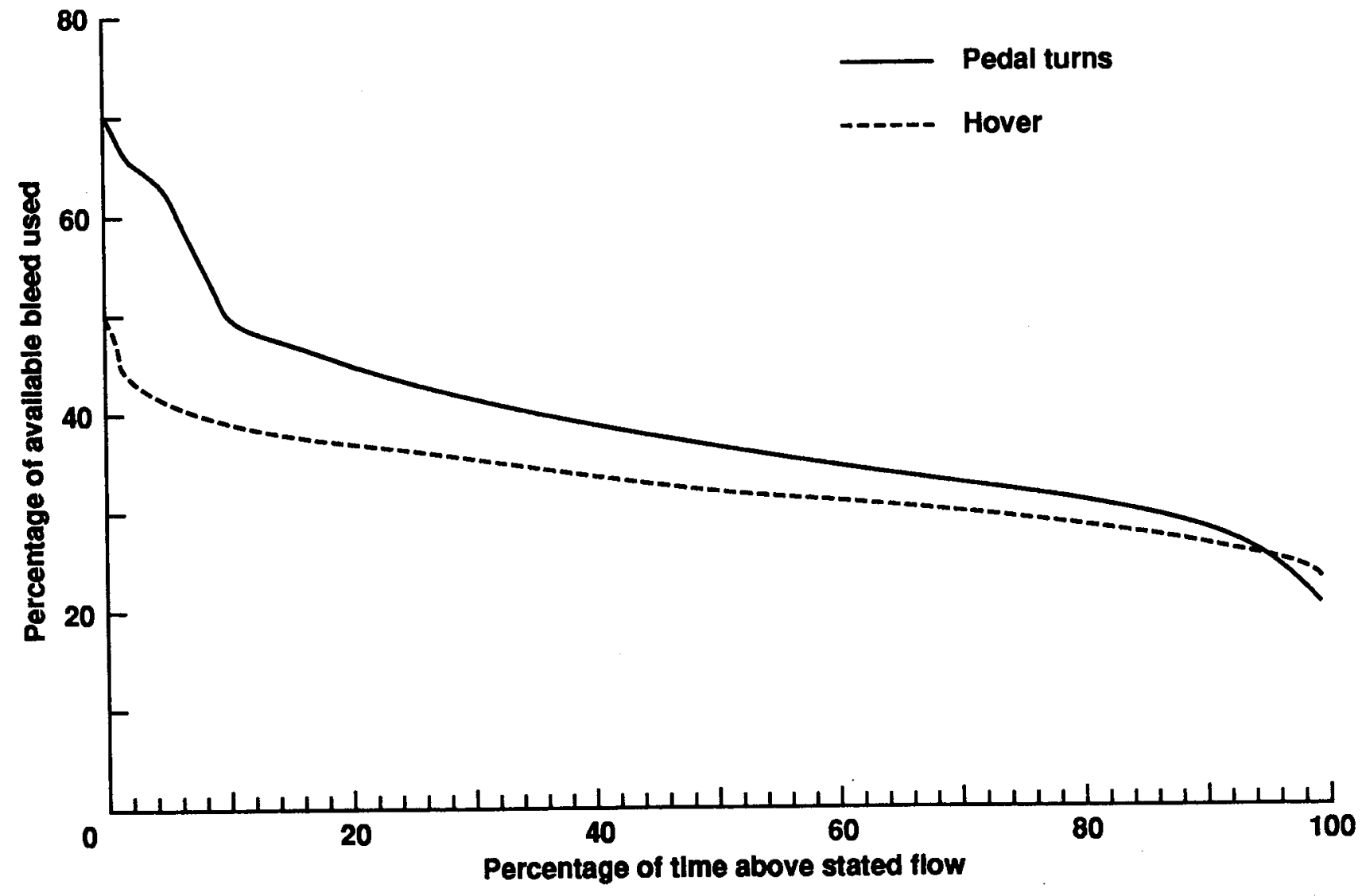

Figure 13. Percentage of available RCS bleed air used during pedal turns. 


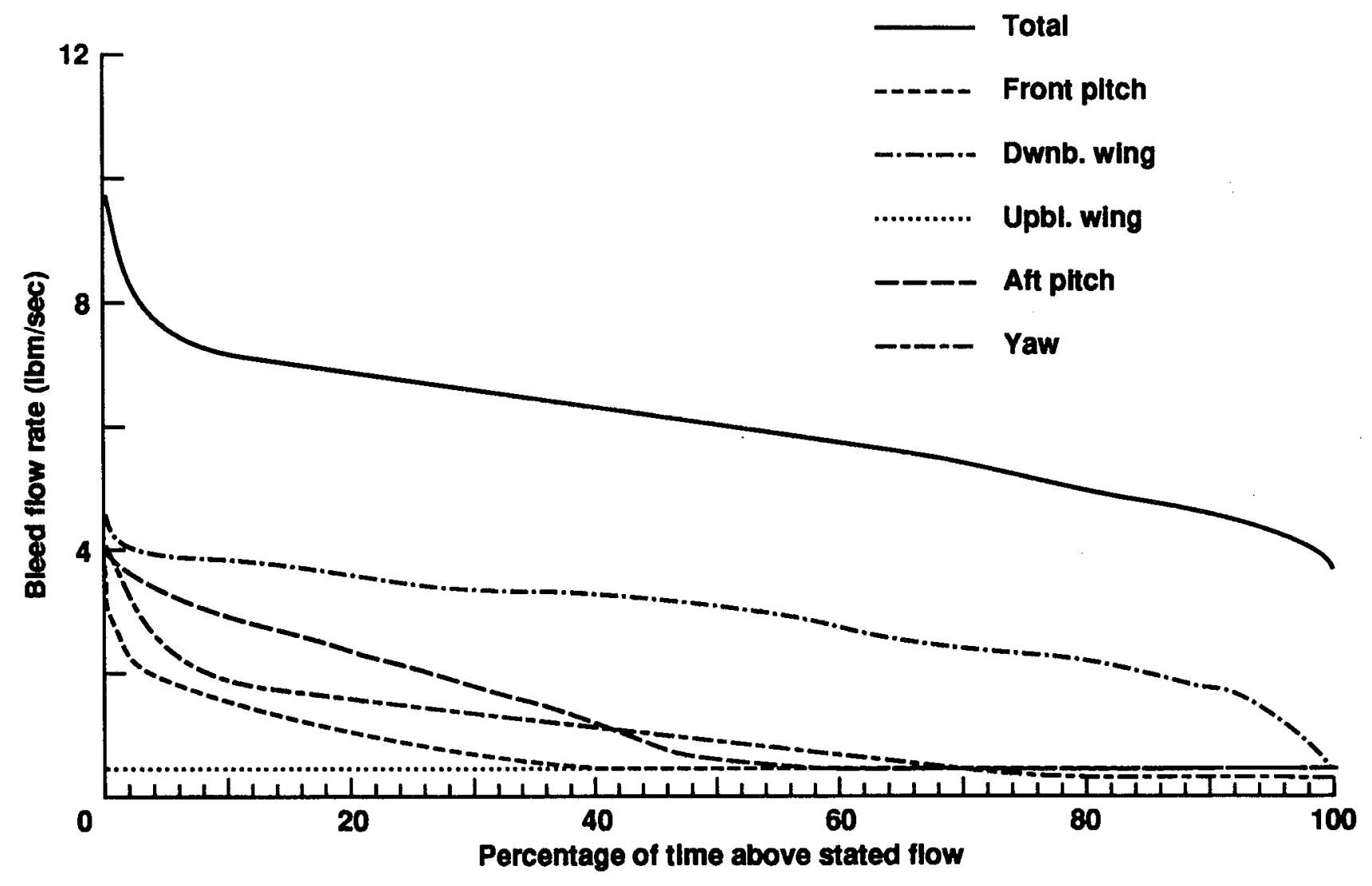

Figure 14. RCS bleed air usage during arrested descents. 


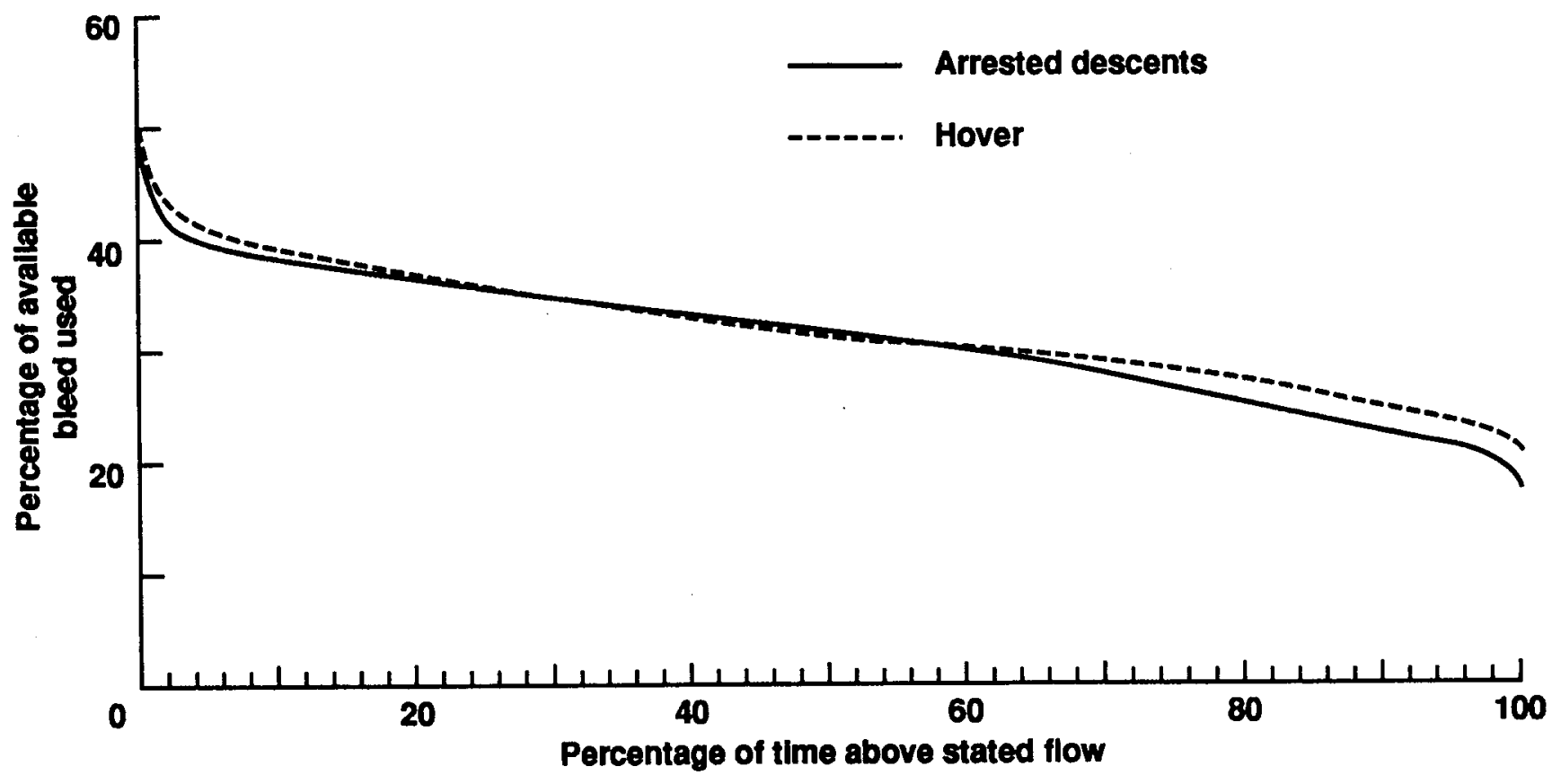

Figure 15. Percentage of available RCS bleed air used during arrested descents. 


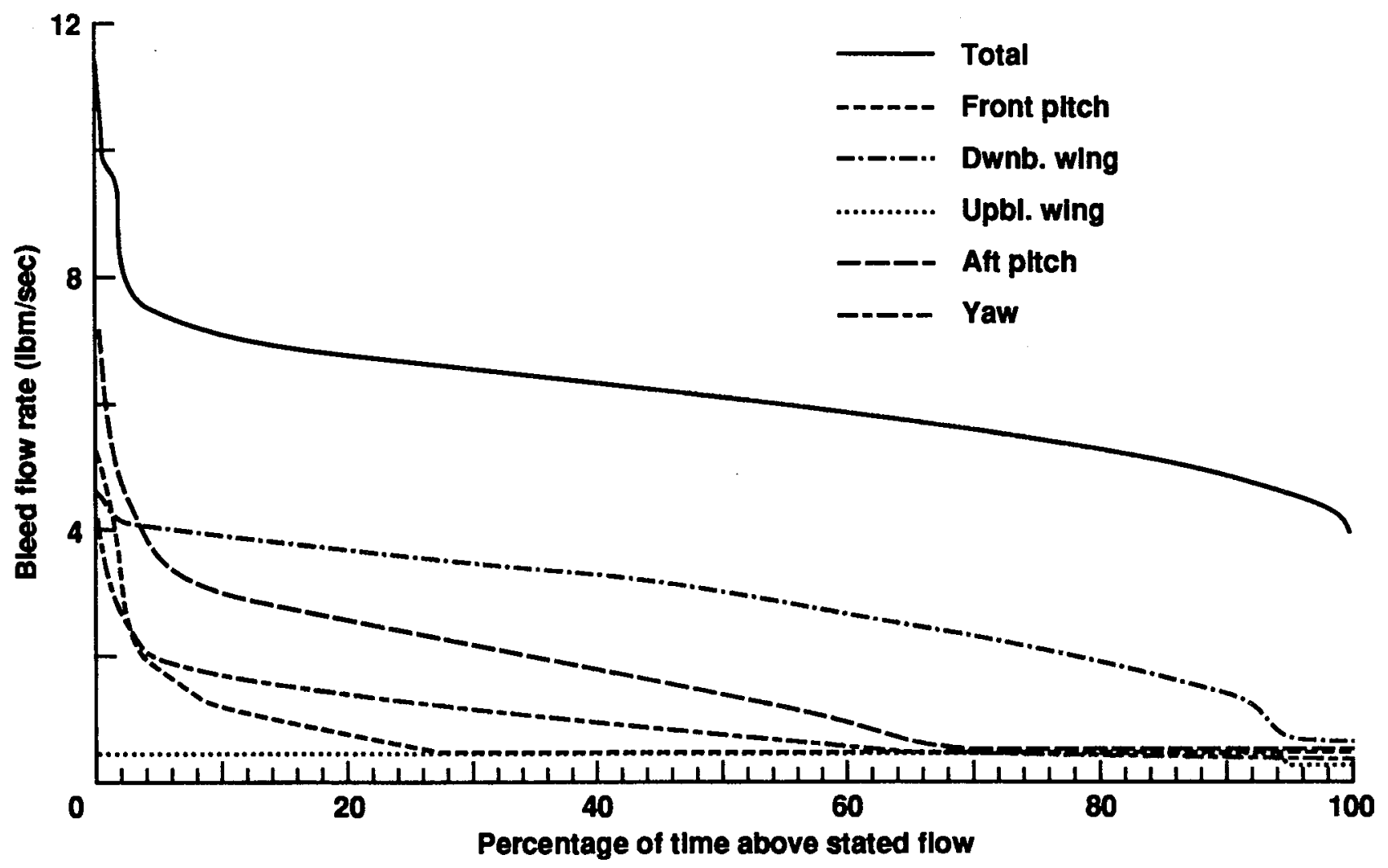

Figure 16. RCS bleed air usage during vertical landings. 


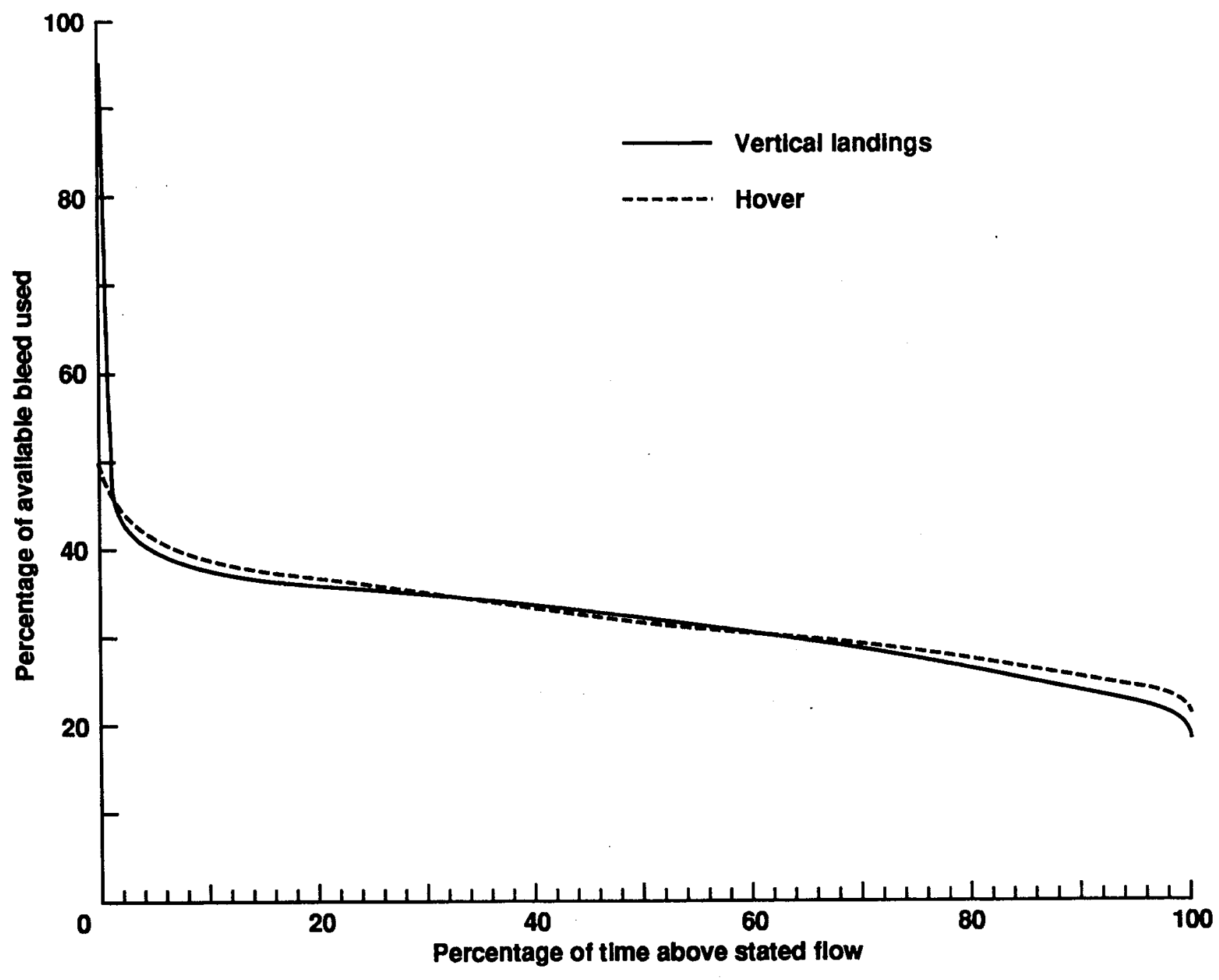

Figure 17. Percentage of available RCS bleed air used during vertical landings. 


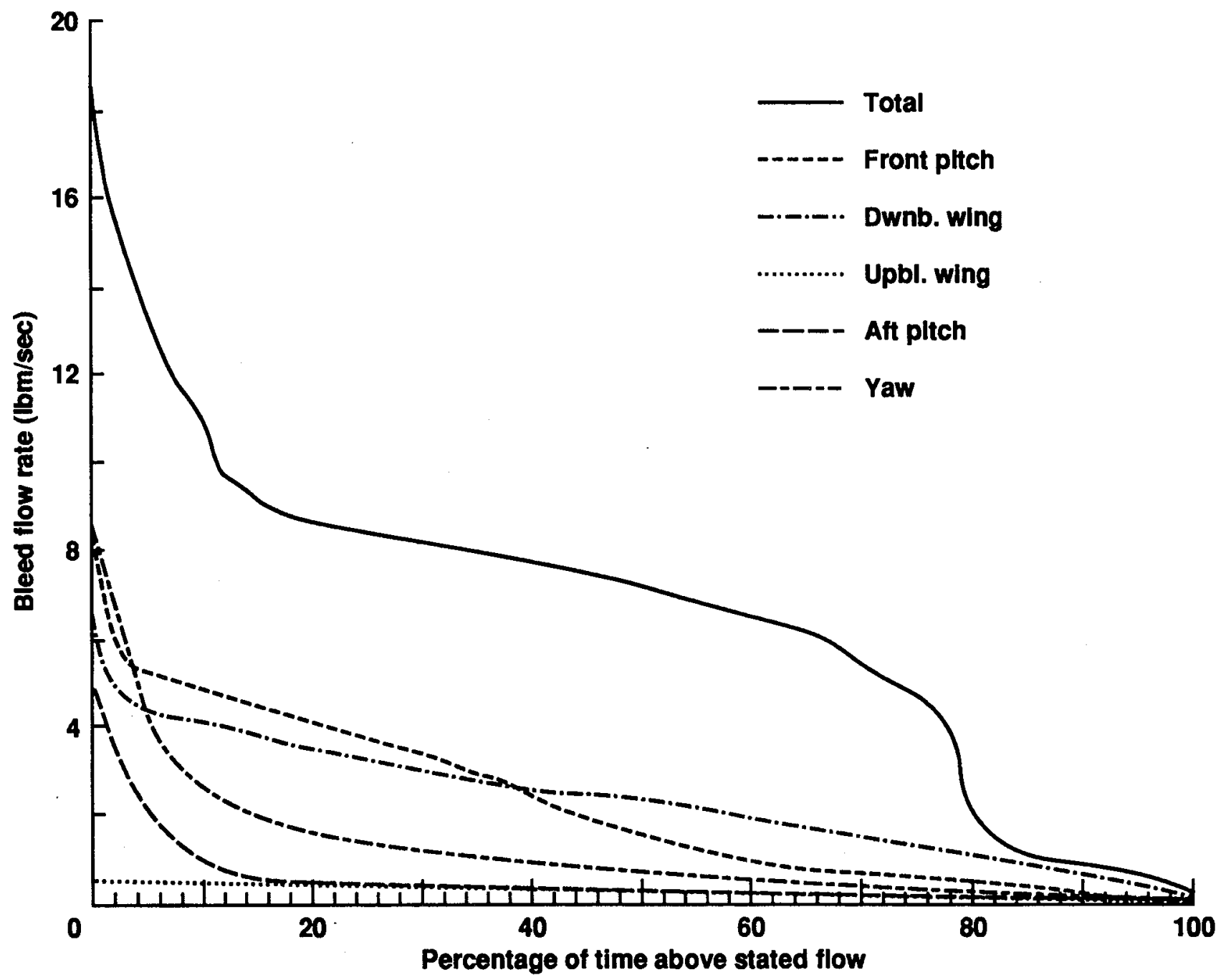

Figure 18. RCS bleed air usage during short takeoff. 


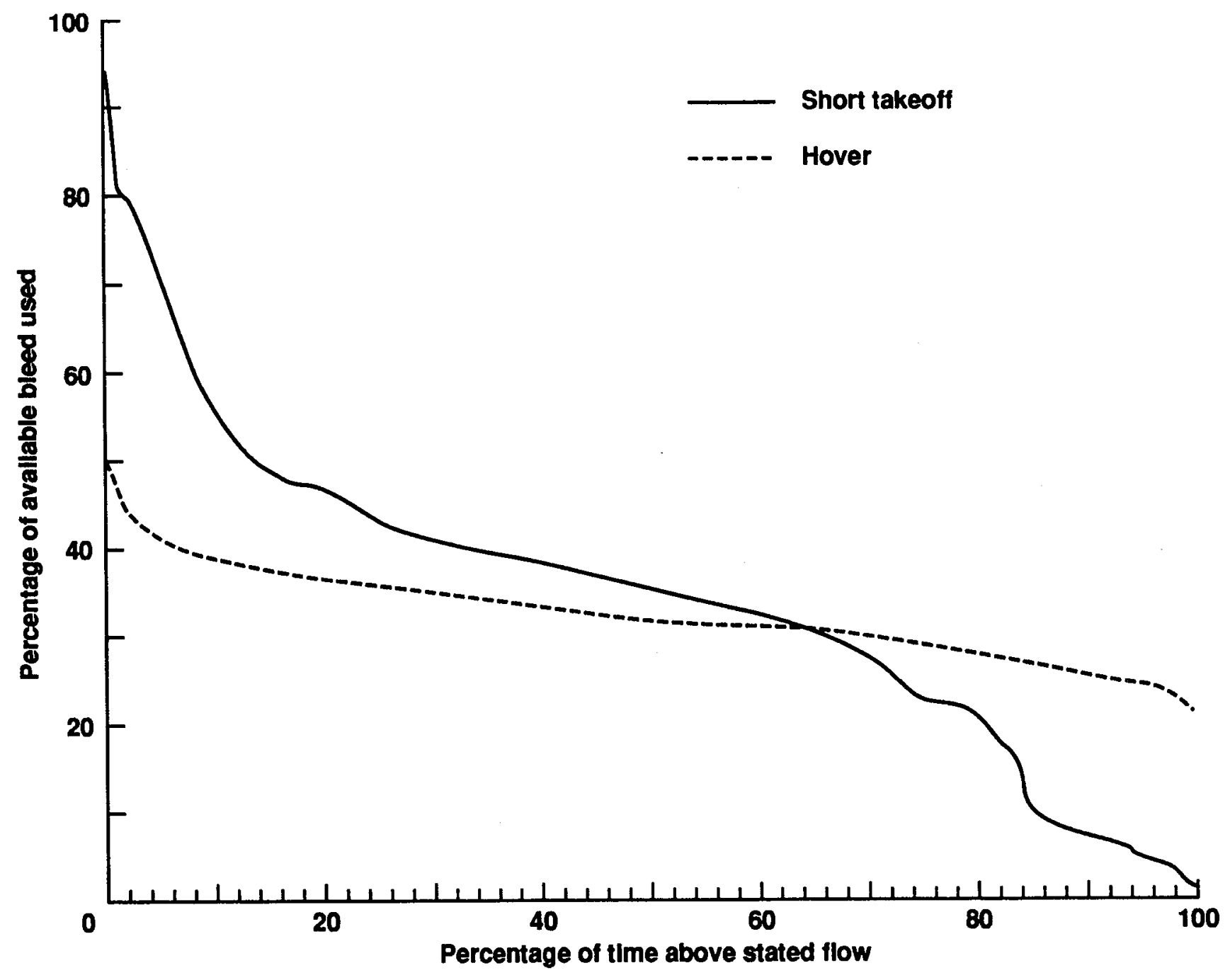

Figure 19. Percentage of available RCS bleed air used during short takeoff. 


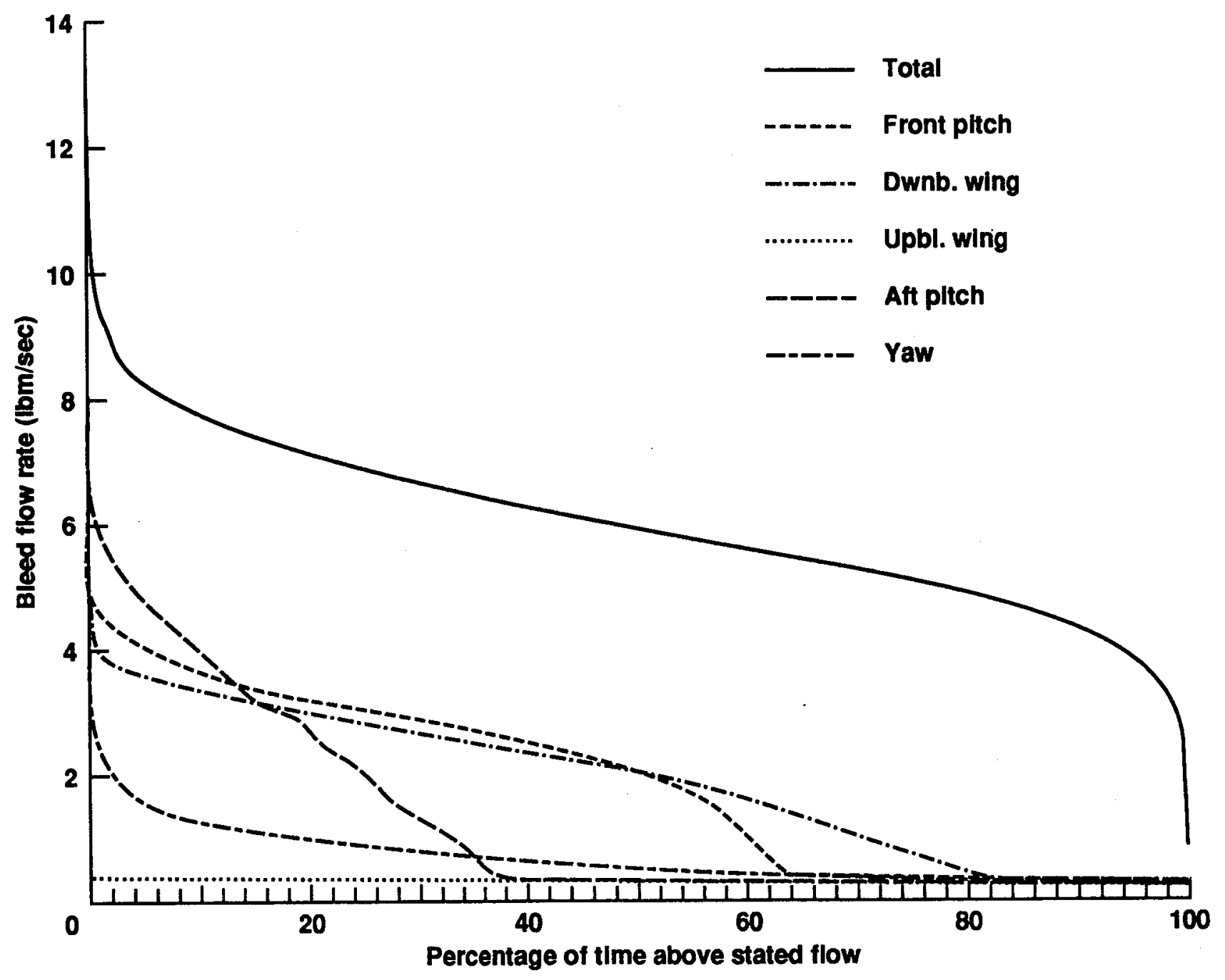

Figure 20. RCS bleed air usage during approach and transition to hover. 


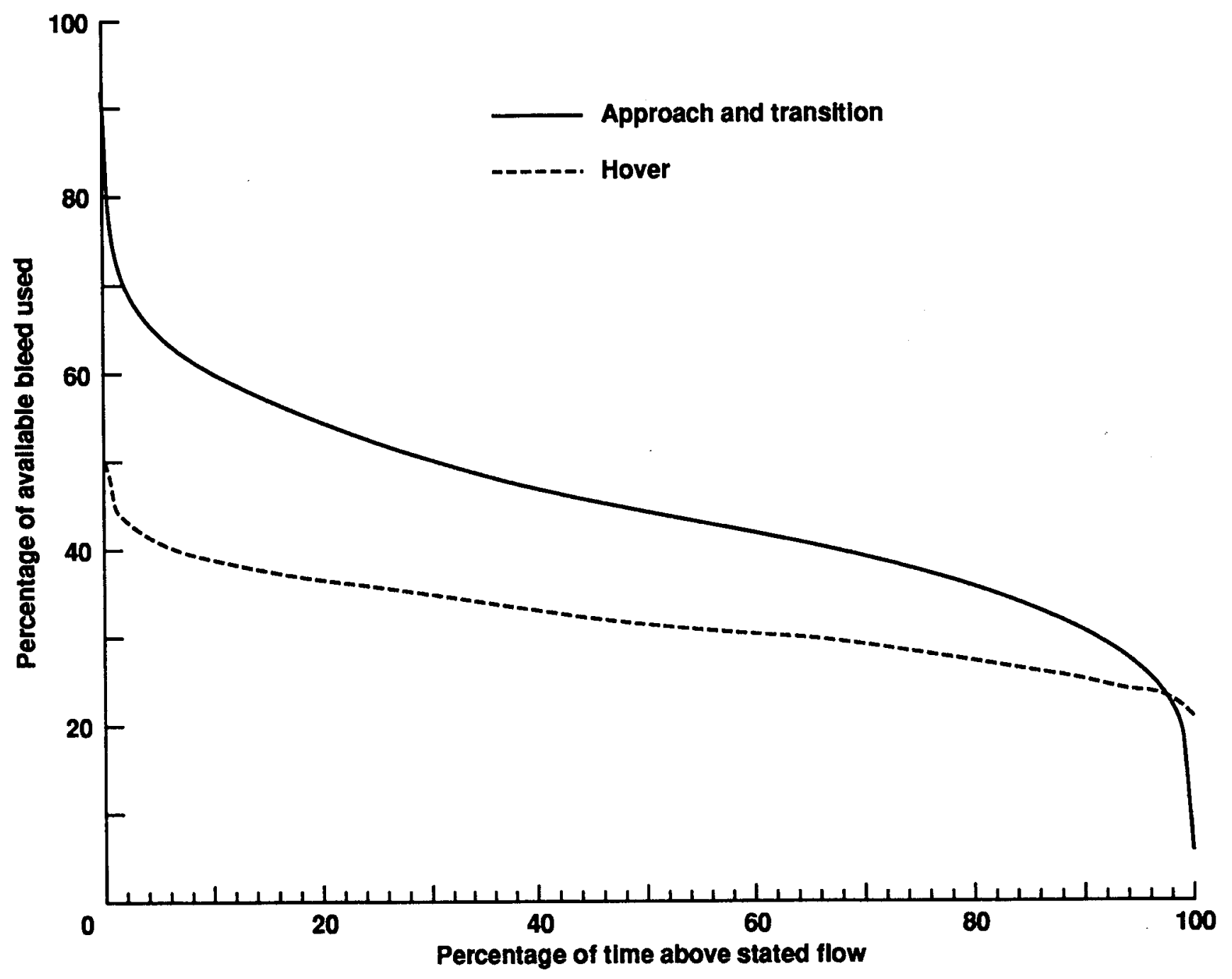

Figure 21. Percentage of available RCS bleed air used during approach and transition to hover. 


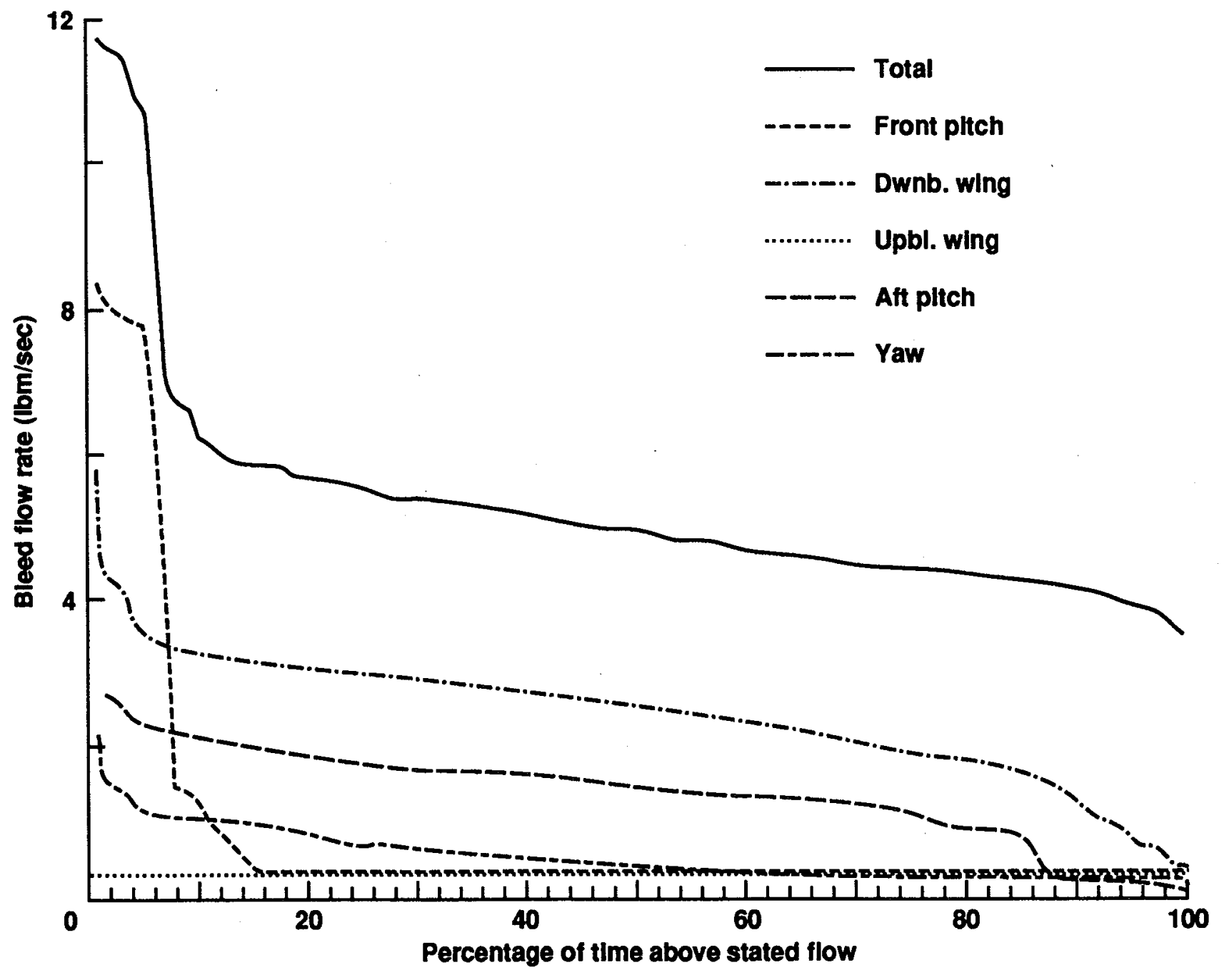

Figure 22. RCS bleed air usage during slow, rolling landing. 


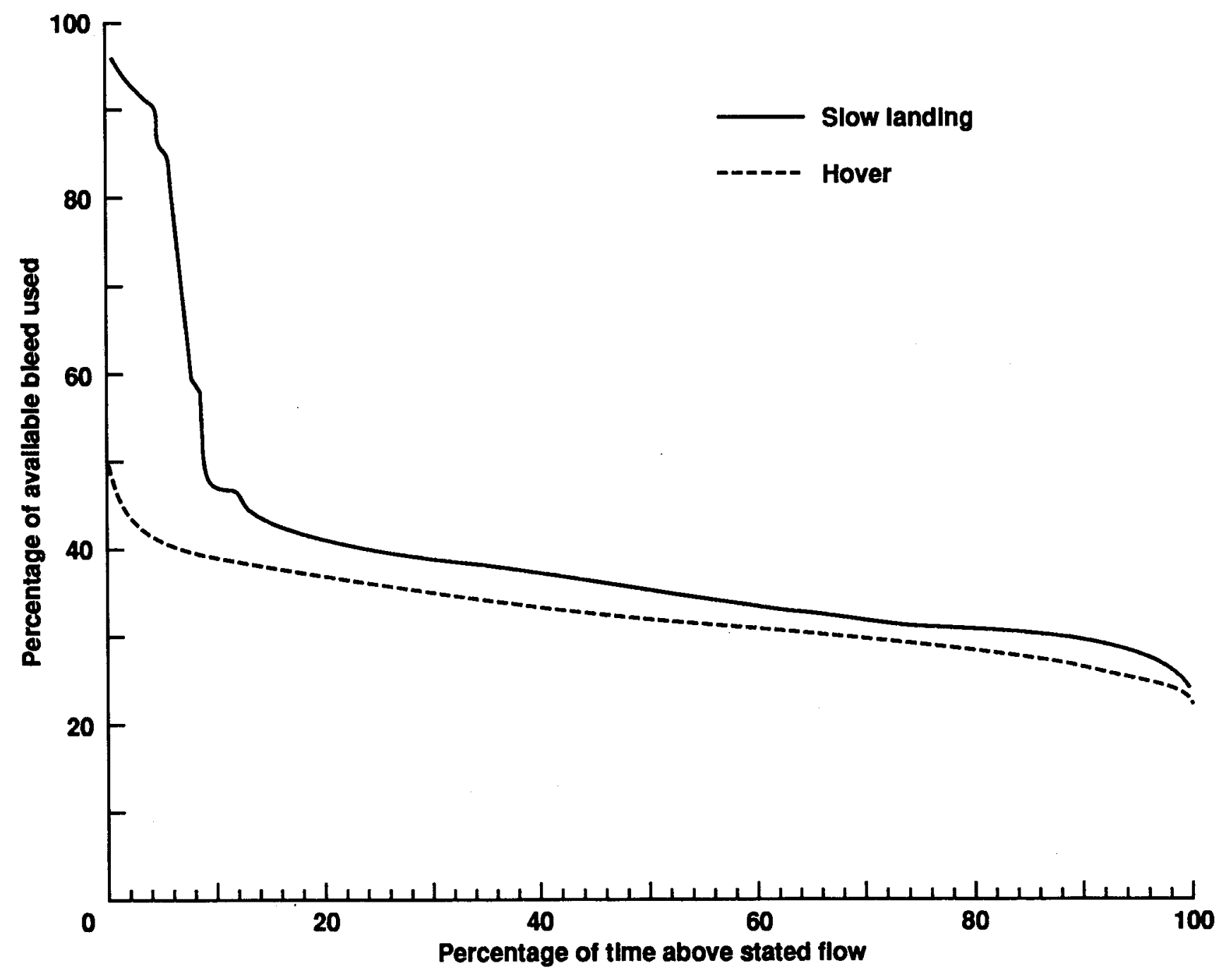

Figure 23. Percentage of available RCS bleed air used during slow landing. 


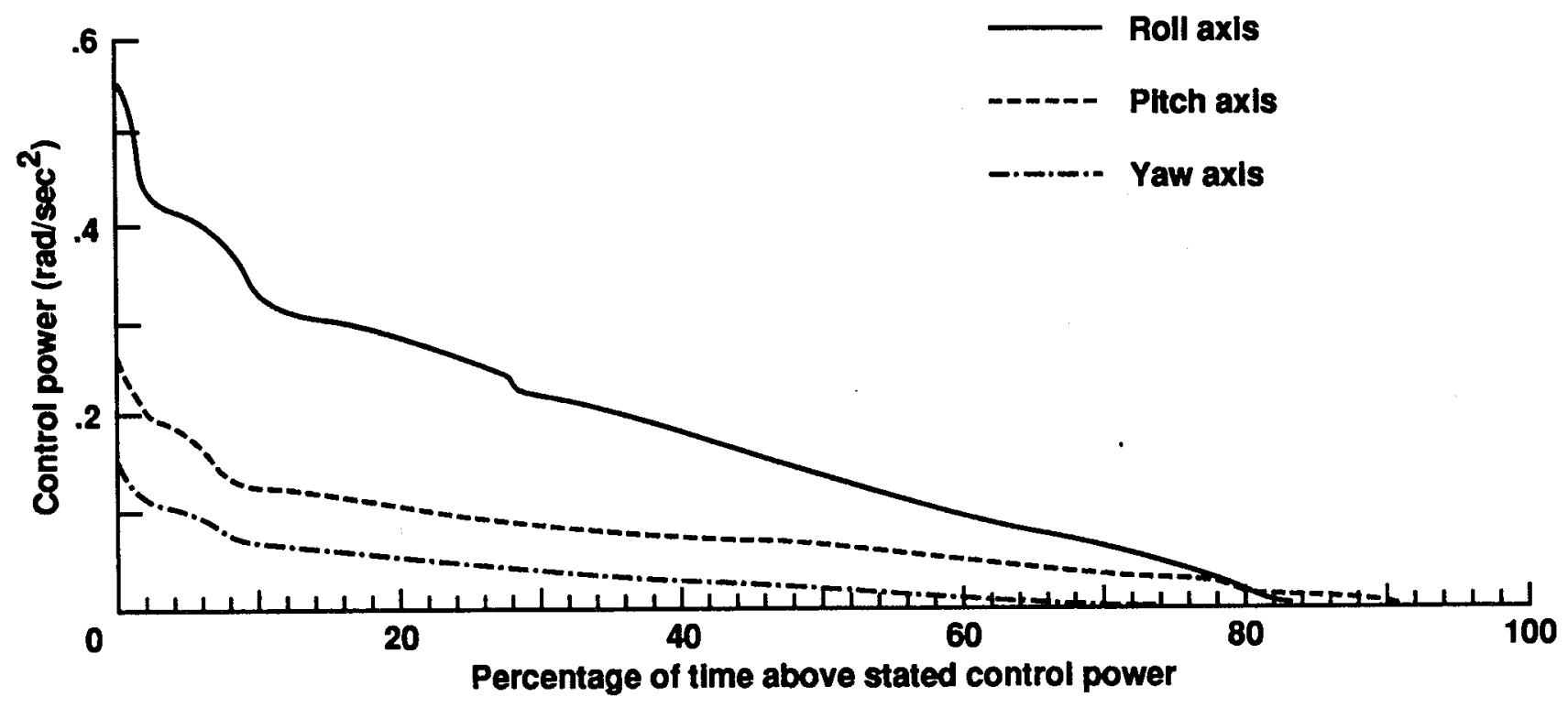

Figure 24. RCS control power during hover. 


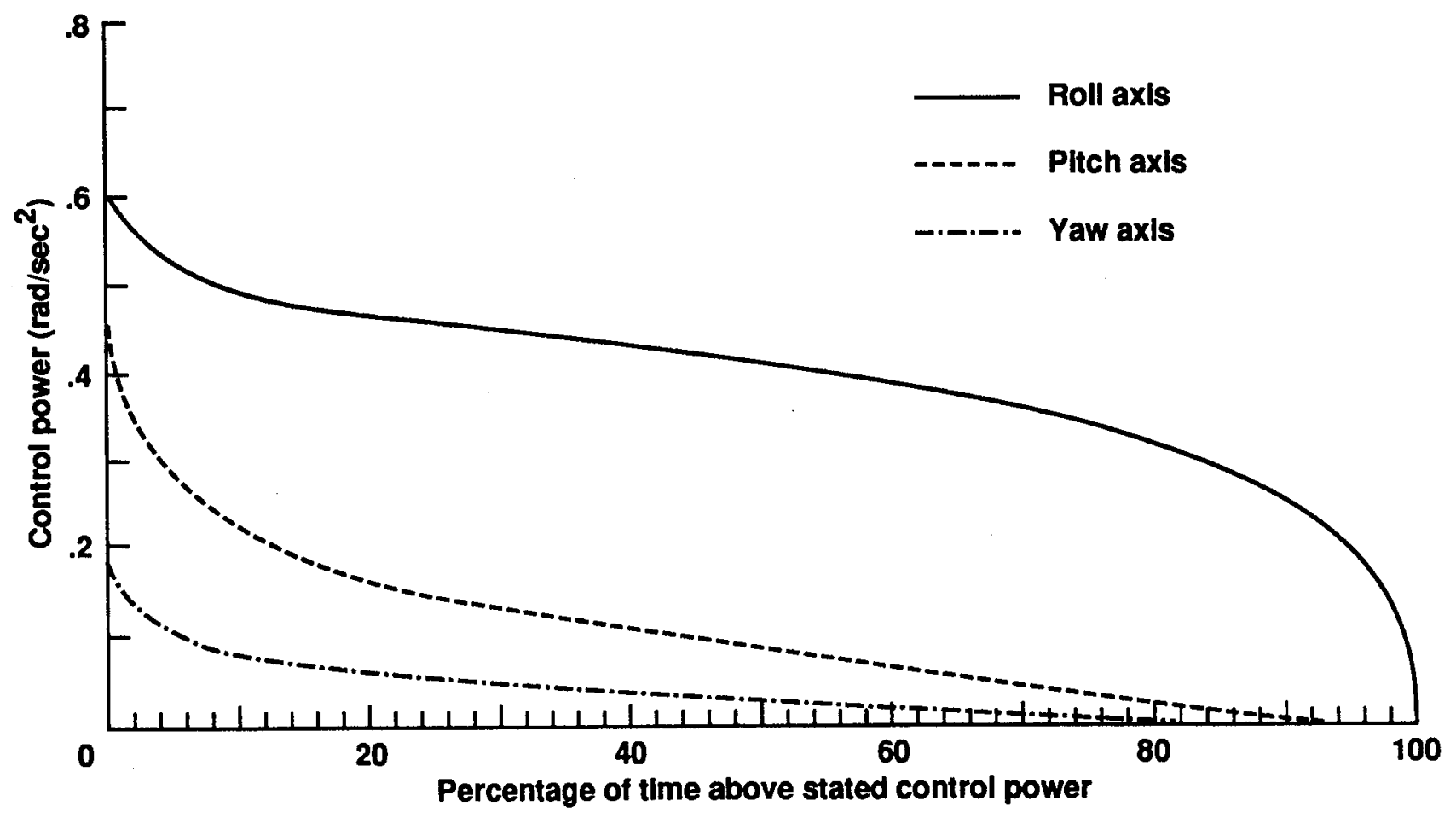

Figure 25. RCS control power during longitudinal translations. 


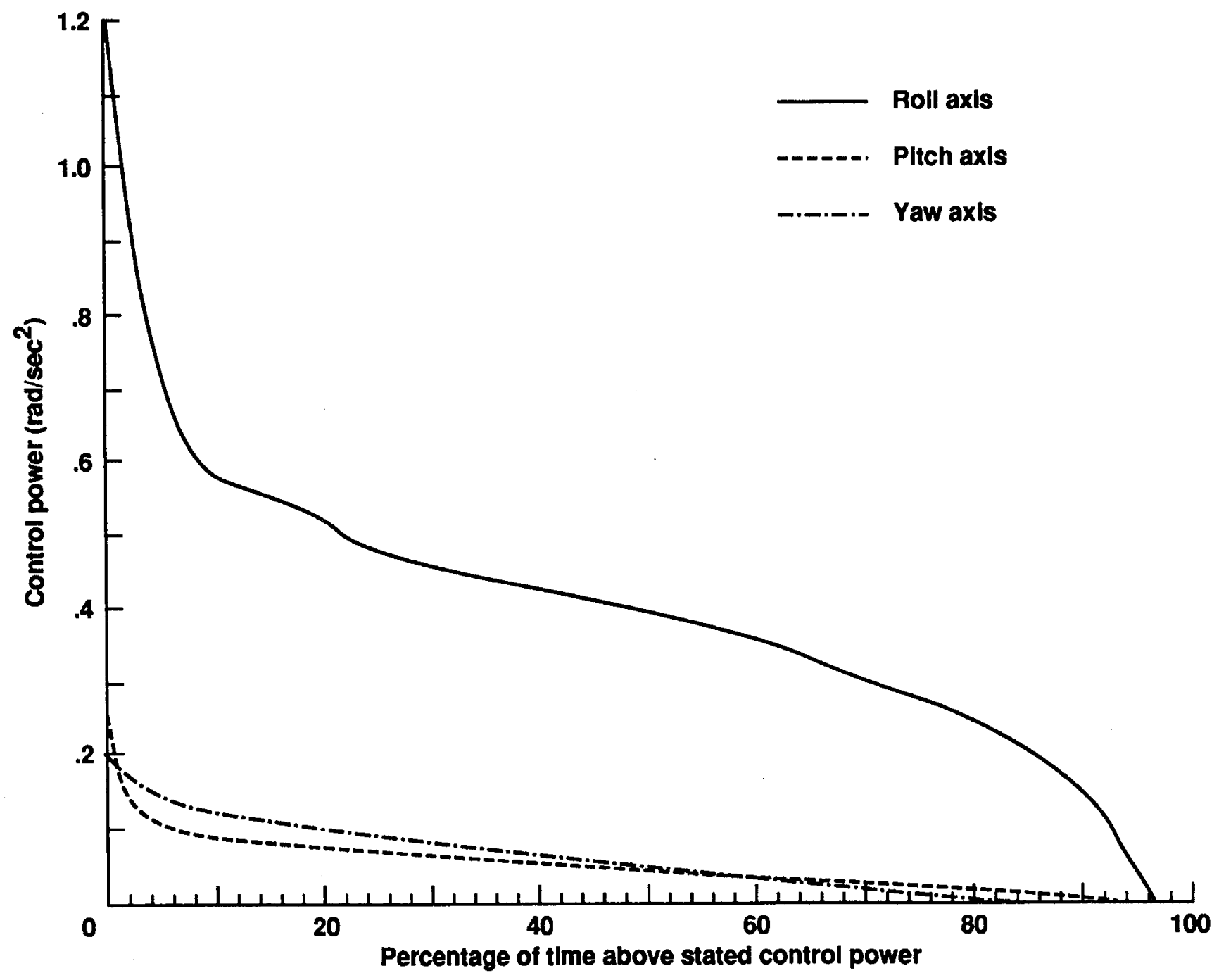

Figure 26. RCS control power during lateral translations. 


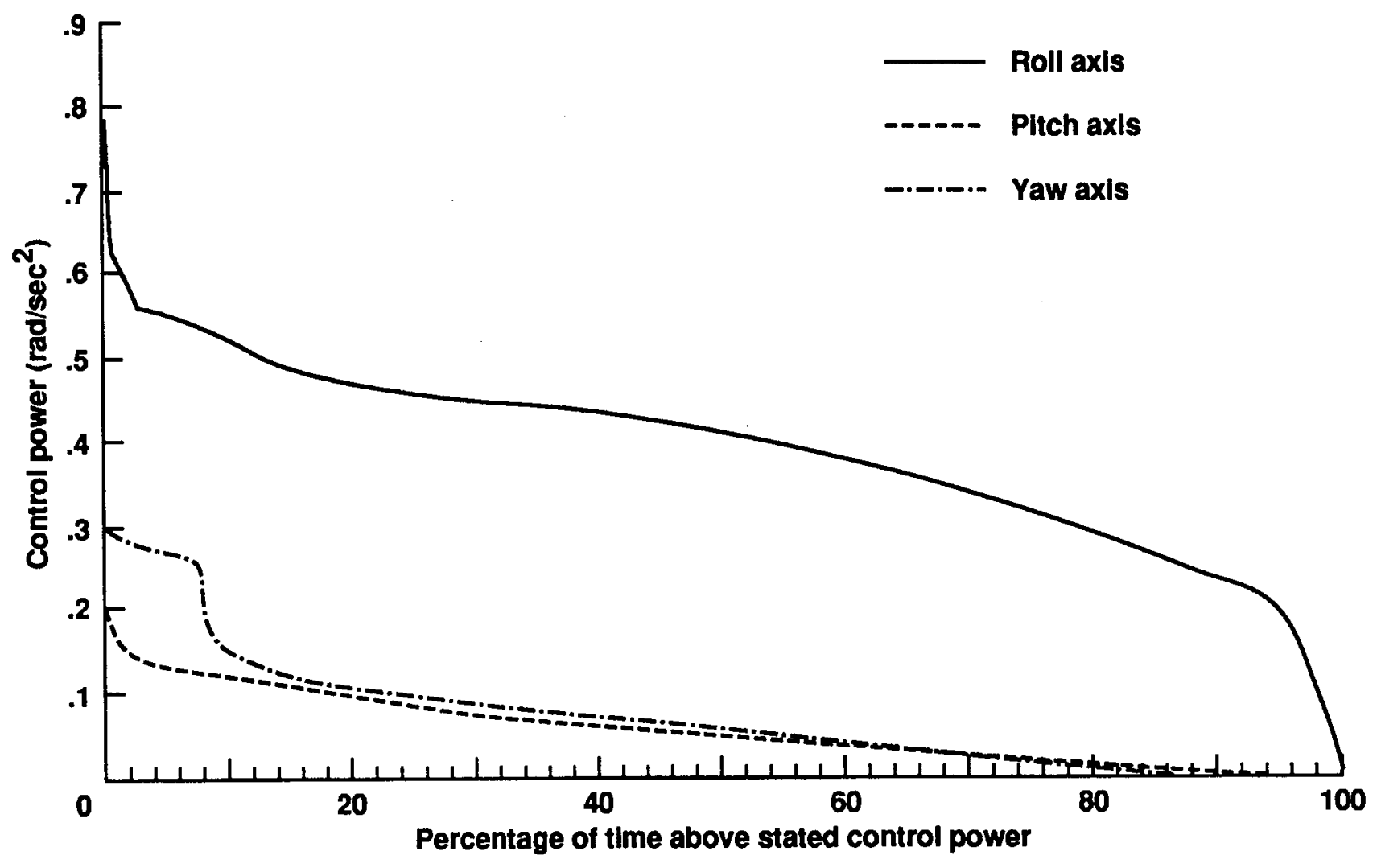

Figure 27. RCS control power during pedal turns. 


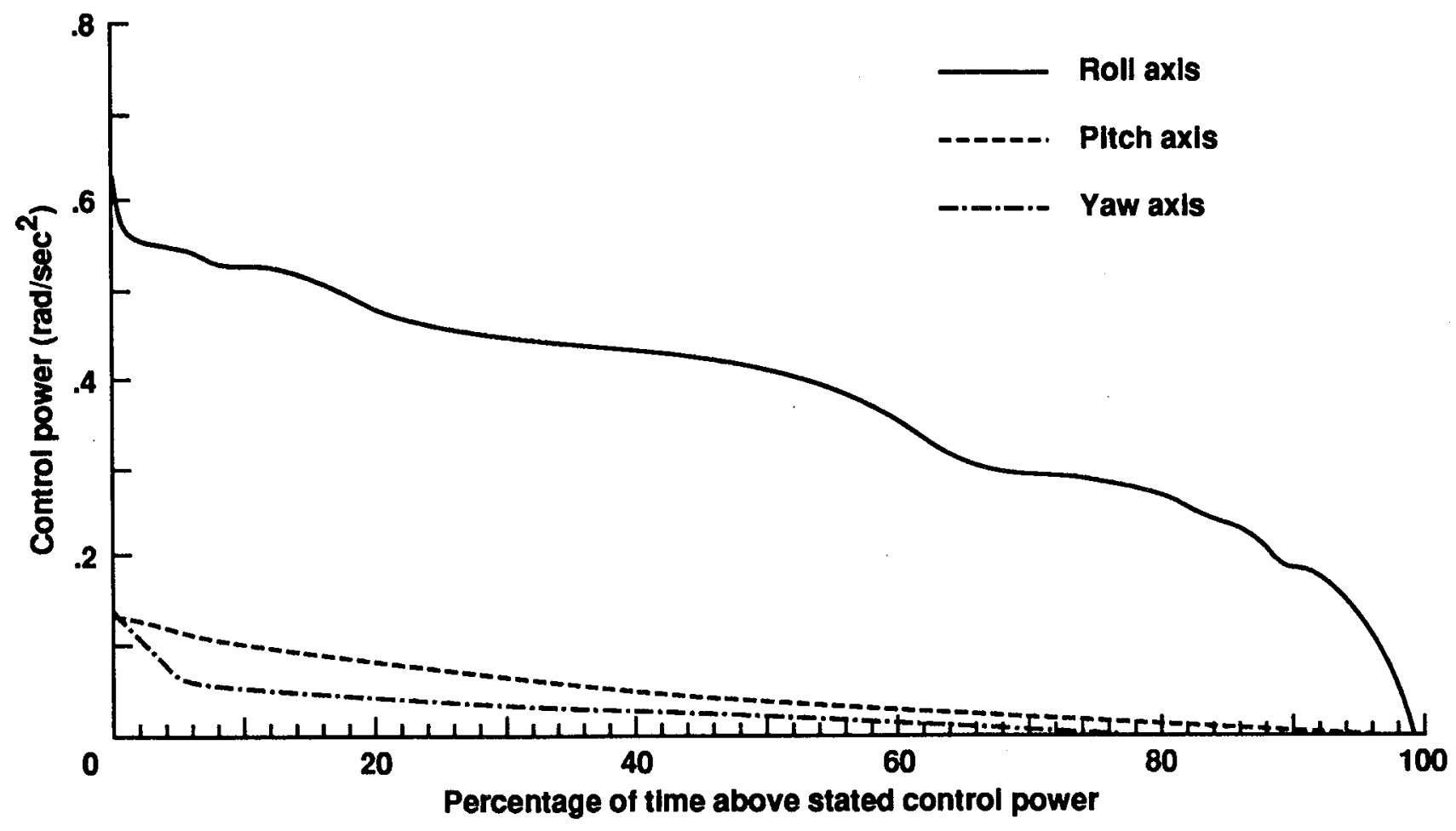

Figure 28. RCS control power during arrested descents. 


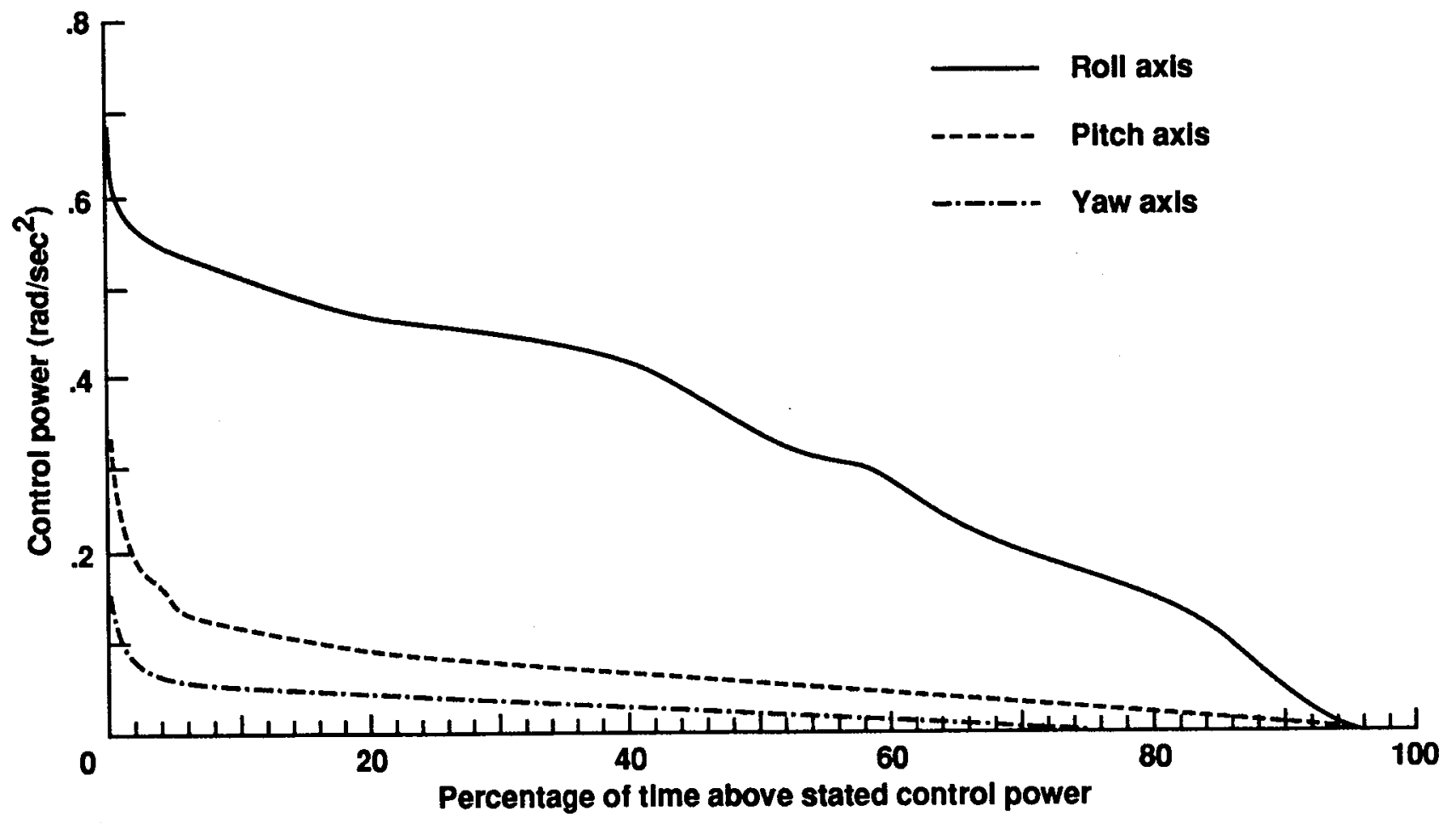

Figure 29. RCS control power during vertical landings. 

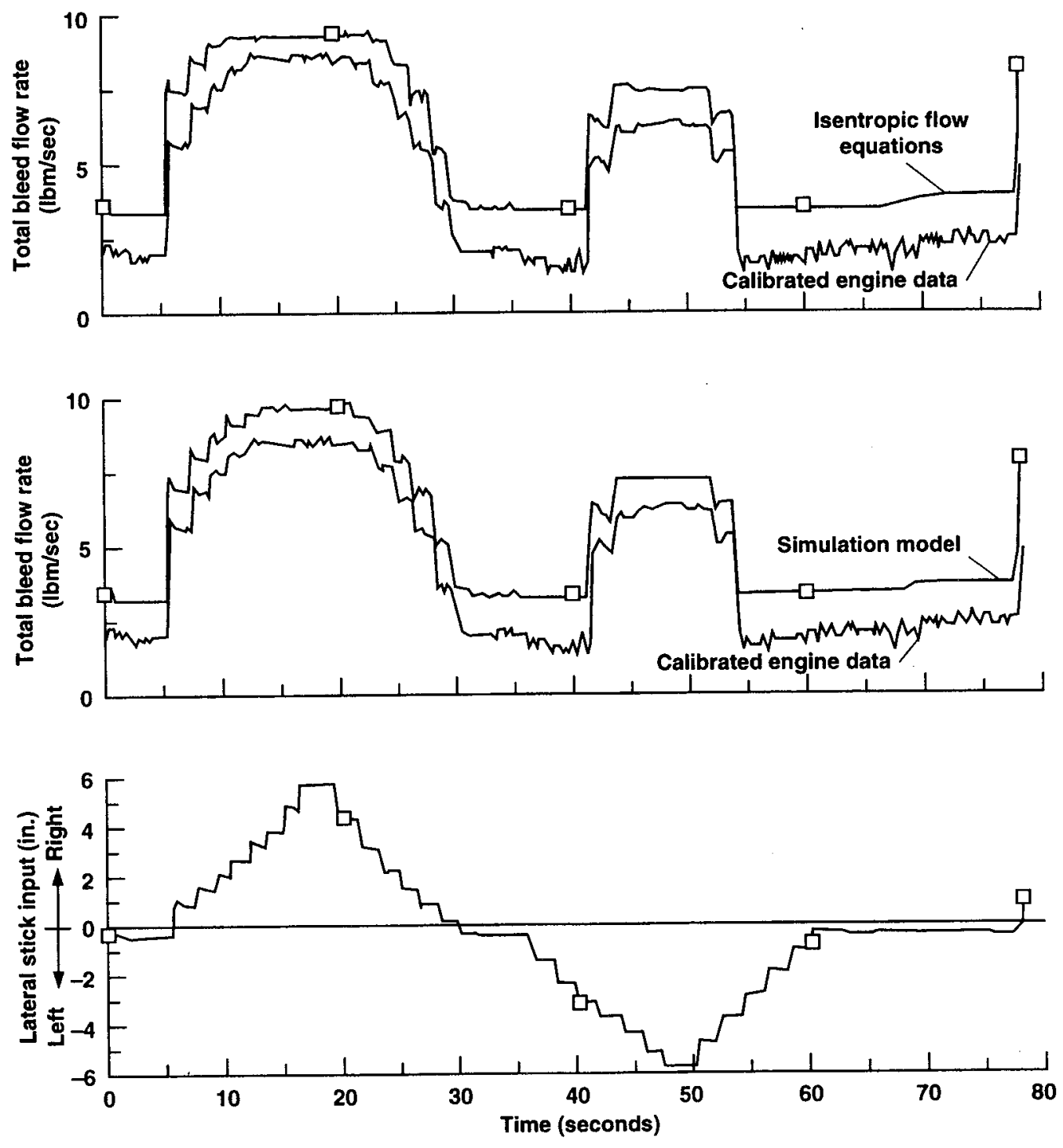

Figure A1. Total bleed flow comparison for left roll valve deflections, $\delta_{n}=40^{\circ}, 90 \%$ maximum rpm, original mfp. 

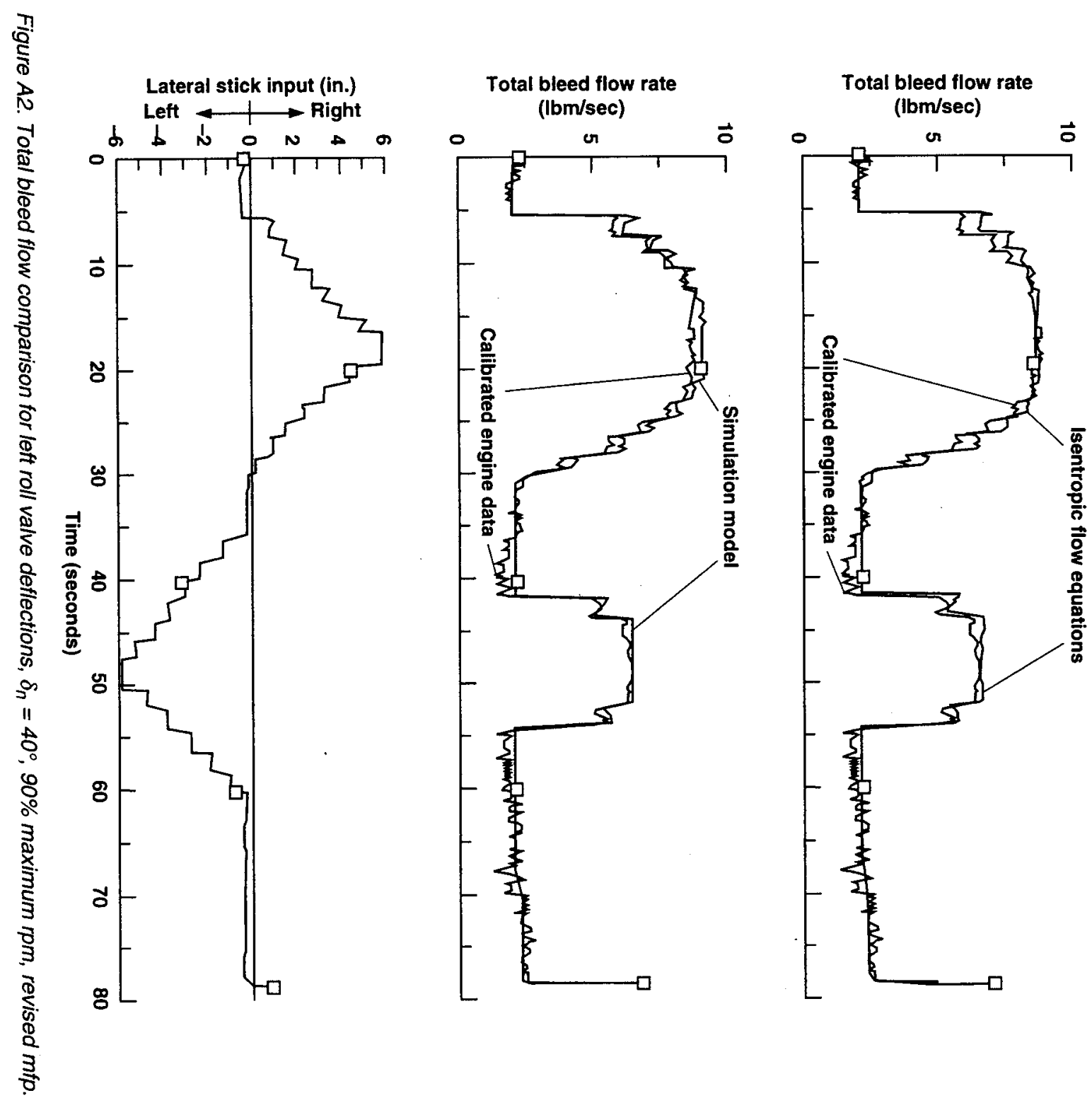
Public reporting burden for this collection of information is estimated to average 1 hour per response, including the time for reviewing instructions. searching existing data sources, gathering and maintaining the data needed, and completing and reviewing the collection of information. Send comments regarding this burden estimate or any other aspect of this Davis Highway. Suite 1204, Arlington, VA 22202-4302, and to the Office of Management and Budget, Paperwork Reduction Project (0704-0188), Washington, DC 20503.
1. AGENCY USE ONLY (Leave blank)
2. REPORT DATE
April 1994
3. REPORT TYPE AND DATES COVERED
Technical Memorandum

\section{TITLE AND SUBTITLE}

YAV-8B Reaction Control System Bleed and Control Power Usage in Hover and Transition

6. AUTHOR(S)

Paul F. Borchers, Ernesto Moralez III, Vernon K. Merrick, and

Michael W. Stortz

7. PERforming organization NAME(S) AND ADdRESS(ES)

Ames Research Center

Moffett Field, CA 94035-1000

9. SPONSORING/MONITORING AGENCY NAME(S) AND ADDRESS(ES)

National Aeronautics and Space Administration

Washington, DC 20546-0001

\section{SUPPLEMENTARY NOTES}

Point of Contact: Paul F. Borchers, Ames Research Center, MS 211-2, Moffett Field, CA 94035-1000; (415) 604-6115
5. FUNDING NUMBERS

533-02-37

8. PERFORMING ORGANIZATION

REPORT NUMBER

A-93080

10. SPONSORING/MONITORING AGENCY REPORT NUMBER

NASA TM-104021

12a. DISTRIBUTION/AVAILABILITY STATEMENT

12b. DISTRIBUTION CODE

Unclassified - Unlimited

Subject Category 08

\section{ABSTRACT (Maximum 200 words)}

Using a calibrated Rolls-Royce Pegasus engine and existing aircraft instrumentation and pressure taps, total and individual nozzle reaction control system (RCS) bleed flow rates have been measured on a YAV-8B Harrier during typical short takeoff, transition, hover, and vertical landing maneuvers. RCS thrust forces were calculated from RCS nozzle total pressure measurements, and control power was determined from the moments produced by these thrusts and the aircraft's moments of inertia. These data document the characteristics of the YAV-8B RCS with its basic stability augmentation system (SAS) engaged. Advanced control system designs for the YAV-8B can be compared to the original SAS based on the total bleed use and the percentage of available bleed used. In addition, the peak and mean values of the bleed and control power data can be used for sizing the reaction controls for a future short takeoff and vertical landing (STOVL) aircraft.

14. SUBJECT TERMS

STOVL, Reaction control systems, STOVL stability and control, Preliminary design

\begin{tabular}{l|l}
\hline 17. SECUAITY CLASSIFICATION & 18. SECURITY CLASSIFICATION \\
OF REPORT & OF THIS PAGE \\
Unclassified & Unclassified \\
\hline
\end{tabular}

15. NUMBER OF PAGES

48

16. PRICE CODE

$\mathrm{A03}$

19. SECURITY CLASSIFICATION OF ABSTRACT

To.

20. LIMITATION OF ABSTRACT 